\section{U.S. DEPARTMENT OF ENERCY}

\section{Office of}

ENERGY EFFICIENCY \& RENEWABLE ENERGY

\title{
Land-Based Wind Energy Siting: A Foundational and Technical Resource
}

August 2021 


\section{Disclaimer}

This work was prepared as an account of work sponsored by an agency of the United States Government. Neither the United States Government nor any agency thereof, nor any of their employees, nor any of their contractors, subcontractors or their employees, makes any warranty, express or implied, or assumes any legal liability or responsibility for the accuracy, completeness, or any third party's use or the results of such use of any information, apparatus, product, or process disclosed, or represents that its use would not infringe privately owned rights. Reference herein to any specific commercial product, process, or service by trade name, trademark, manufacturer, or otherwise, does not necessarily constitute or imply its endorsement, recommendation, or favoring by the United States Government or any agency thereof or its contractors or subcontractors. The views and opinions of authors expressed herein do not necessarily state or reflect those of the United States Government or any agency thereof, its contractors or subcontractors. 


\section{Authors}

The authors of this report are:

Corrie Christol, National Renewable Energy Laboratory (NREL)

Frank Oteri, NREL

Michael Laurienti, NREL.

\section{Acknowledgments}

This material is based upon work supported by the U.S. Department of Energy (DOE) Office of Energy Efficiency and Renewable Energy, specifically the Wind Energy Technologies Office under Contract Number DE-AC36-08GO28308.

The authors would like to thank Maggie Yancey (DOE) and Mary Hallisey (NREL) for their support, review, and dedication to this project, which made publishing this resource possible.

The authors would like to acknowledge the valuable guidance and input provided by the steering committee during the development of this resource. Their feedback and review proved invaluable. Steering committee members include:

- Hilary Clark, American Clean Power Association

- Katharine Collins, Southeast Wind Coalition

- Dave Iadarola, CORE Consultants, Inc.

- Sarah Mills, University of Michigan

- Jack Morgan, National Association of Counties

- Rachel Petry, Southern Power

- Dahvi Wilson, Apex Clean Energy.

The authors would like to thank the following contributors for their input and technical expertise:

- Jocelyn Brown-Saracino, Patrick Gilman, Coryne Tasca, and Liz Hartman, DOE

- Michael Speerschneider, American Clean Power Association

- Jessi Wyatt, Great Plains Institute

- Michael Azeka, EDF Renewables

- Gregory Brinkman, Dave Corbus, Bethany Frew, Cris Hein, Aaron Levine, Anthony Lopez, and Patrick Moriarty, NREL

- Sheri Anstedt and Katie Wensuc, NREL.

This report was prepared by the National Renewable Energy Laboratory for the U.S. Department of Energy Office of Energy Efficiency and Renewable Energy Wind Energy Technologies Office. 


\section{List of Acronyms and Abbreviations}

\begin{tabular}{|c|c|}
\hline ADLS & aircraft detection lighting system \\
\hline $\mathrm{ACP}$ & American Clean Power \\
\hline Berkeley Lab & Lawrence Berkeley National Laboratory \\
\hline CWA & Clean Water Act \\
\hline DOE & U.S. Department of Energy \\
\hline DOD & U.S. Department of Defense \\
\hline EIA & Energy Information Administration \\
\hline ESA & Endangered Species Act \\
\hline FAA & Federal Aviation Administration \\
\hline FERC & Federal Energy Regulatory Commission \\
\hline $\mathrm{ft}$ & foot \\
\hline $\mathrm{Hz}$ & hertz \\
\hline $\mathrm{m}$ & meter \\
\hline MW & megawatt \\
\hline NEPA & National Environmental Policy Act \\
\hline NEWEEP & New England Wind Energy Education Project \\
\hline NREL & National Renewable Energy Laboratory \\
\hline NYSERDA & New York State Energy Research and Development Authority \\
\hline O\&M & operation and maintenance \\
\hline PPA & power purchase agreement \\
\hline USFWS & U.S. Fish and Wildlife Service \\
\hline USGS & U.S. Geological Survey \\
\hline USWTDB & U.S. Wind Turbine Database \\
\hline
\end{tabular}

Definitions for some of the terminology used in this report can be found in the EIA glossary. 


\section{Introduction}

\section{Purpose}

This land-based wind energy siting resource was created by the U.S. Department of Energy Wind Energy Technologies Office's WINDExchange initiative and presents foundational information about land-based utility-scale wind energy that local decision makers can use when making community decisions about wind energy development. Consolidated, accessible, and easy to understand, this information resource focuses on land-based wind energy from the community perspective and examines siting-related impacts and mitigation strategies. Other impacts and strategies exist, such as those related to economics, climate, health, water, emissions, and waste; however, they are not covered in this resource. For more information on economic considerations, see the "Land-Based Wind: Economic Development Guide" and "Advancing the Growth of the U.S. Wind Industry: Federal Incentives, Funding, and Partnership Opportunities.”

The intended audience for this guide is county-level decision officials, as they are often responsible for approving both wind energy ordinances and applicable permits needed for wind energy development. This guide may also provide relevant information to decision makers from other government jurisdictions and interested community members.

\section{How To Use This Resource}

This resource is divided into two sections:

1. Land-Based Wind Energy Development Overview. An introduction to wind energy technology and community considerations that provides readers with a general understanding of wind energy.

2. Siting Elements: Considerations, Strategies, and Resources. An examination of the following 12 siting elements, including a technical overview, what communities can expect, and resources for more information:

○ Construction

○ Decommissioning

○ Electrical and power systems

○ Environment

○ Land and airspace use

○ Property value

- Road use and maintenance

○ Safety

- Shadow flicker

- Signal interference

○ Sound

○ Viewshed. 


\section{Methodology}

\section{Ordinance Review}

To develop this resource, the authors reviewed county-level wind energy ordinances from 20 states to identify the various elements that communities have addressed within their wind energy ordinances. The authors selected states based on their installed capacity, regional representation, and regulatory models. To ensure the focus remained on communities that were creating ordinances that could support wind energy development, the authors selected counties that have existing and/or proposed wind energy projects.

The authors conducted this ordinance review using a Microsoft Excel database built specifically for the project. The authors also created parameters for the database after reading a sample portion of wind energy ordinances from selected states and identifying the common elements and classifiable factors within them. With a template in place, the authors used more than 120 ordinances to populate the database. Finally, the authors assembled additional information to characterize each of the communities whose ordinances were included in the review, such as county population, population density, total megawatts installed, and if the county had existing or pending wind energy projects.

In addition to the ordinance review, the authors formed a steering committee to provide guidance and support regarding the content of this siting resource and to ensure that the final product accurately represents community-focused, land-based wind energy siting impacts. To achieve this goal, the steering committee featured individuals from various wind energy and land-use backgrounds including academic institutions, developers, energy providers, stakeholders, consultants, county associations, and trade organizations.

\section{Siting Elements}

This resource focuses on the 12 siting elements identified during the ordinance review and refined by the steering committee. Of these elements, the committee determined six specific elements to be higher priority. Each priority element includes an in-depth discussion of considerations, best practices, and mitigation strategies. The "Considerations" section of each element includes a technical overview and focus on applicable federal, state, and local regulations. The "Best Practices and Mitigation Strategies" section of each element introduces methods that are used to evaluate potential impacts and the strategies that communities can use to lessen those impacts. Finally, the "Resources" section of each element provides additional sources of information, such as peer-reviewed research papers, organizations, and websites.

\section{Terminology}

Throughout this resource, the authors use certain terms to consolidate language, specify intent, and avoid confusion. For instance, the term "community" refers to the multiple types of local government jurisdictions that oversee the siting regulation of wind energy projects. This commonly includes counties, townships, or municipalities.

The term "impact" refers to the physical effects a community can experience during the construction, operation, and decommissioning of a wind energy development project.

"Regulation" refers to the authority delegated to federal, state, or local agencies to create and apply rules. In this resource, the term is often used within the context of land-use planning and rules or 
codes that are developed to determine whether planning permission is granted (Cornell Law School undated).

"Zoning" refers to the division of a city or county by legislative regulations into areas, or zones, that specify allowable uses for real property and size restrictions for buildings within these areas; a program that implements policies of the general plan (Institute for Local Government 2010).

"Wind farm" refers to a group of wind turbines (from a few to hundreds) operated collectively as a single facility. The term may also be referred to as a wind power plant, wind project, wind energy development, wind development, wind energy conversion system, or wind facility. 


\section{Table of Contents}

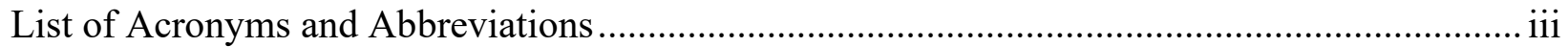

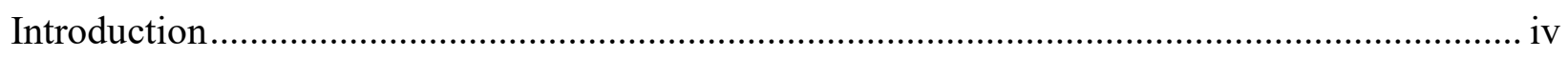

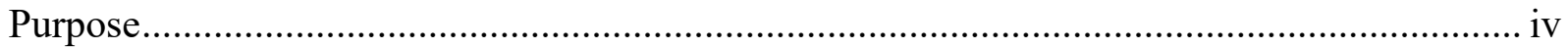

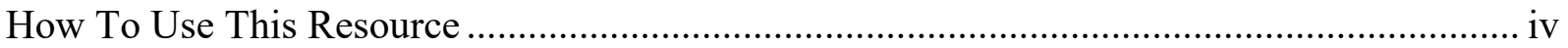

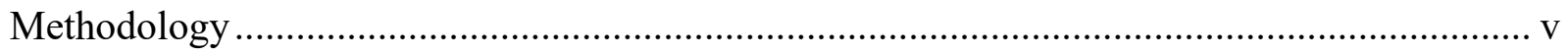

1 Land-Based Wind Energy Development Overview ……………………………............ 1

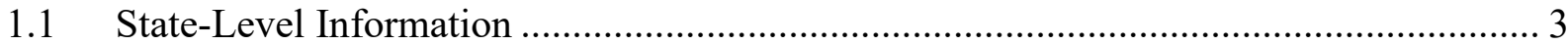

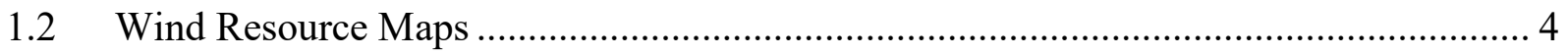

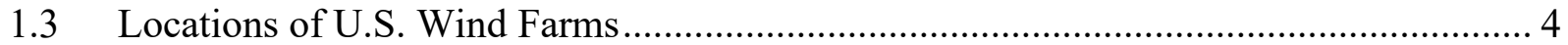

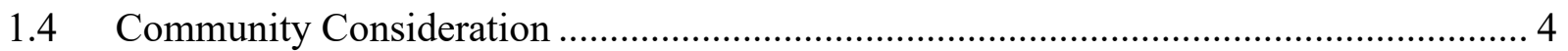

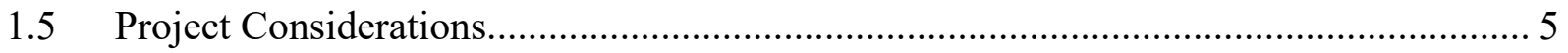

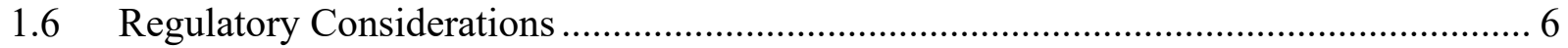

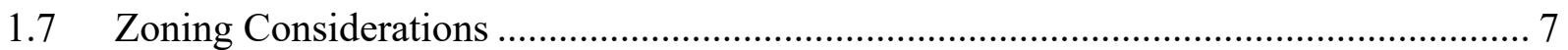

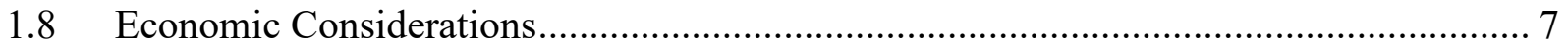

1.9 Transmission, Interconnection, and Offtake Agreements ............................................. 7

2 Siting Elements: Considerations, Strategies, and Resources ............................................. 9

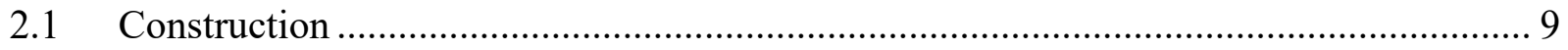

2.2 Decommissioning ................................................................................................ 11

$2.3 \quad$ Electrical and Power Systems …………………............................................. 15

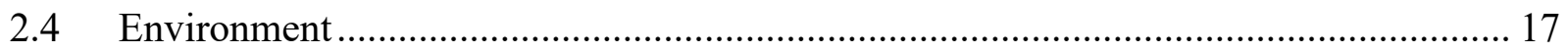

2.5 Land and Airspace Use ………………………................................................... 25

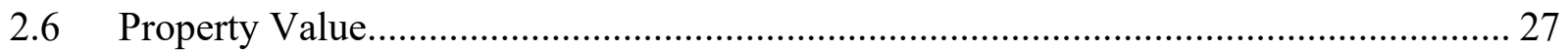

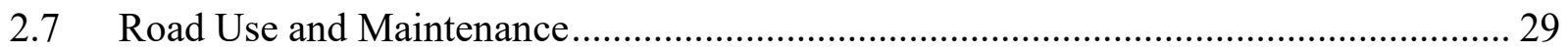

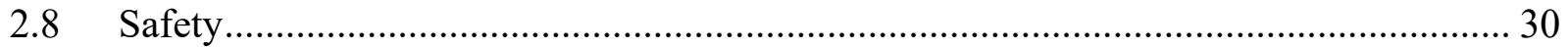

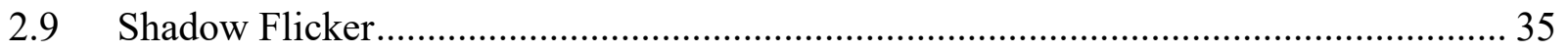

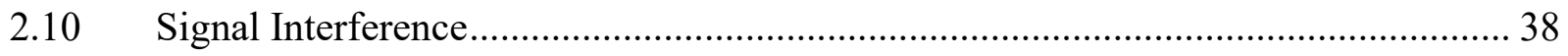

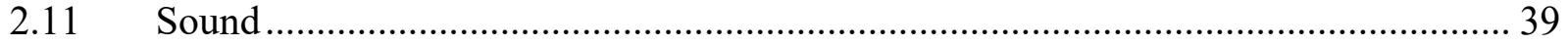

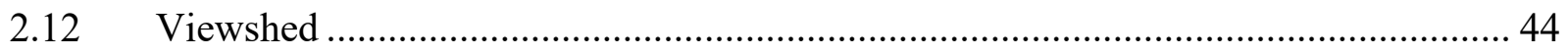

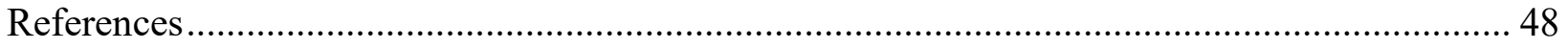




\section{List of Figures}

Figure 1. U.S. electricity generation by type and percentage for 2020. Source: EIA (2021) ........ 1

Figure 2. Overlay of wind and solar power purchase agreement (PPA) prices with the levelized price of natural gas to showcase the cost competitiveness of the two renewable energy resources. Source: Lawrence Berkeley National Laboratory (2020) ................................... 2

Figure 3. The average nameplate capacity, hub height, and rotor diameter for land-based wind from 1998 to 2019. Source: Berkeley Lab (2020) ........................................................... 3

Figure 4. The development of a new wind power plant is a multistep process that can take years to complete. Source: American Clean Power (2020) .................................................... 5

Figure 5. Wind turbine components on agricultural land that will still be used after construction. Photo by Joe Ross

Figure 6. Foundations comprise most of the overall mass of a project when considering windturbine- and project-related infrastructure. Photo from Avangrid Renewables, National Renewable Energy Laboratory (NREL) 41780.

Figure 7. Wind turbine towers (in the background) being erected and attached with blades, nacelles, and hubs. Photo by Dave Iadarola

Figure 8. Decommissioned 3-MW GE/Alstom research wind turbine at NREL's Flatirons Campus. Photo by Werner Slocum, NREL 62412

Figure 9. Wind turbine access roads can account for $38 \%-41 \%$ of nonusable land within a wind energy project's footprint (Diffendorfer and Compton 2014). Photo by Dale Carlson ......... 13

Figure 10. Utility-scale wind turbines and transmission lines at the Cedar Creek Wind Farm in Grover, Colorado. Photo by Dennis Schroeder, NREL 31198.

Figure 11. Birds soar through the sky as the sun sets on a wind farm in Iowa. Photo by sringsmuth.....

Figure 12. Sunrise at a wetland marsh in Bear River Refuge in Utah. Photo by Jerry Whetstone, USFWS

Figure 13. A wind turbine in Indiana located on agricultural land used to grow corn. Photo by

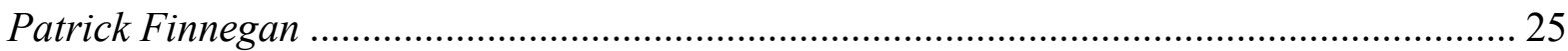

Figure 14. A small plane as it navigates everyday obstructions. Photo by Brad Covington ........ 26

Figure 15. Wind turbines in Lowville, New York, located near existing structures and a pond.

Photo by Mark Plummer. 28

Figure 16. A wind turbine tower being transported through an Illinois town. Photo by risingthermals

Figure 17. The construction of access roads for the Tucannon River Wind Farm near Dayton, Washington. Photo from Portland General Electric ........................................................ 30

Figure 18. A wind turbine setback from farm buildings in rural Iowa. Photo by Don Graham .. 31

Figure 19. Locking door and warning signs on a wind turbine entrance. Photo by Travis ......... 34

Figure 20. A wind turbine shown in the distance from an Illinois farm. Photo by Tracy ........... 35 
Figure 21. The shadow of a wind turbine appears on the land beneath the installation. Photo by Pollys Belivin

Figure 22. The distribution of respondents who reported hearing wind turbines by distance.

Source: Hoen et al. (2019)

Figure 23. A National Park Service map showing existing ambient sound levels across the country. Source: U.S. Department of the Interior (2017).....

Figure 24. Wind turbines approximately 1 mile away from a farm in Kittitas County,

Washington. Photo by Steve Cyr

Figure 25. Wind turbines at the Tucannon River Wind Farm near Dayton, Washington. Photo from Portland General Electric 44

Figure 26. Wind turbines with nighttime lights in Kodiak, Alaska. Photo by naql. 45

Figure 27. Wind turbine without nighttime lighting at the Tucannon River Wind Farm near Dayton, Washington. Photo from Portland General Electric 


\section{Land-Based Wind Energy Development Overview}

According to the Energy Information Administration (EIA), wind energy is the number one renewable energy generation source in the United States (see Figure 1).

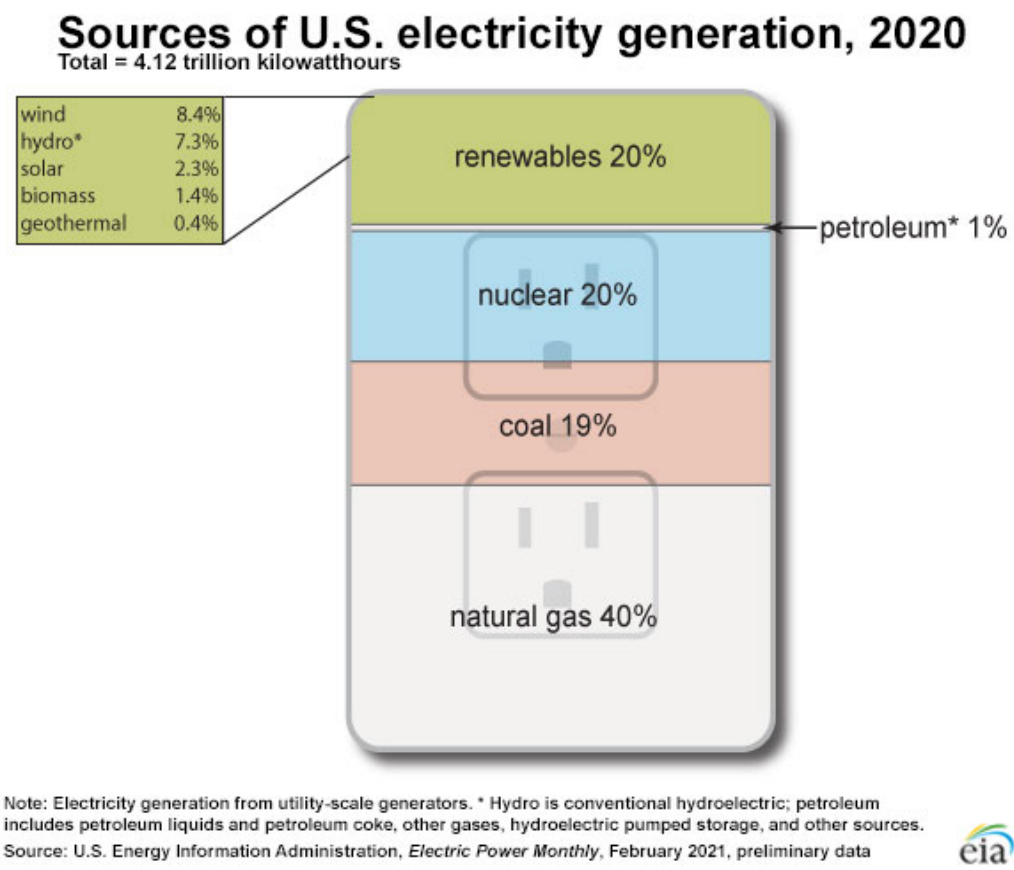

Figure 1. U.S. electricity generation by type and percentage for 2020. Source: EIA (2021)

Since 2010, technological advancements and continued deployment of land-based, utility-scale wind energy have supported a decrease in project costs that has made wind one of the most costeffective forms of energy in many parts of the country (see Figure 2).

Although land-based wind energy has been used for many years in the United States, large utilityscale wind turbines were not common until 2000. At that time, the country's cumulative installed wind energy capacity was less than 1,000 megawatts (MW).

Land-based, utility-scale wind turbines are defined as turbines that exceed $1 \mathrm{MW}$ in size. Other definitions for utility-scale wind include turbines with a 100-kilowatt capacity or more, but this is commonly used to describe the statutory cap for tax implications related to distributed wind. A wind farm (also referred to as a wind power plant, wind energy project, wind energy development, wind development, wind energy conversion system, or wind facility) is a group of turbines (from a few to hundreds) operated collectively as a single facility. Land-based, utility-scale wind farms are typically connected to the power grid, and the electricity produced by these developments can power homes or businesses nearby or far away-depending on power availability and demand. 


\section{Levelized wind and solar PPA prices and levelized gas prices}

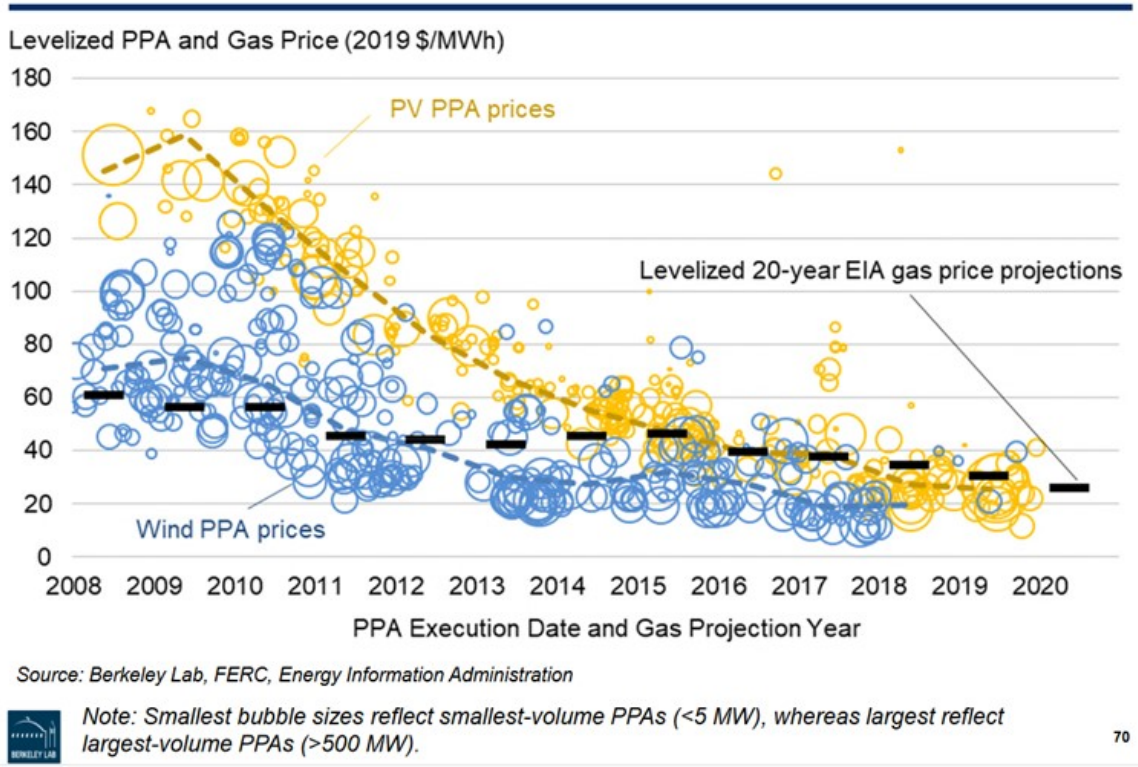

Figure 2. Overlay of wind and solar power purchase agreement (PPA) prices with the levelized price of natural gas to showcase the cost competitiveness of the two renewable energy resources. Source: Lawrence Berkeley National Laboratory (2020)

According to information in the U.S. Wind Turbine Database (USWTDB), the average size of a wind turbine installed in the United States through 2019 was 1.8 MW. According to EIA, 2019 electricity consumption for an average U.S. home was about 877 kilowatt-hours per month. According to Lawrence Berkeley National Laboratory (Berkeley Lab), the average capacity factor for a single wind turbine installed in the United States is 35\%. Given these assumptions, a single wind turbine would generate more than 462,180 kilowatt-hours of energy per monthenough to power more than 527 average U.S. homes. That means that a single wind turbine would generate enough energy in 83 minutes to power an average home for 1 month. This calculation is based on the average wind turbine capacity and capacity factor of the entire U.S. wind fleet and the average household energy use in the United States for 2019.

To produce this much power, utility-scale wind turbines need to be tall enough to reach a strong wind resource. Depending on the local landscape and other development characteristics of a community, wind turbines might be the tallest object in a rural skyline. In 2019, the average installed wind turbine had a total height (base to tip) of approximately 494 feet (ft), with a hub height of approximately $295 \mathrm{ft}$ and a rotor diameter of approximately $397 \mathrm{ft}$ (see Figure 3) (Wiser et al. 2020). The total height of new turbines built in 2019 ranged from approximately $404 \mathrm{ft}$ to approximately $654 \mathrm{ft}$. 


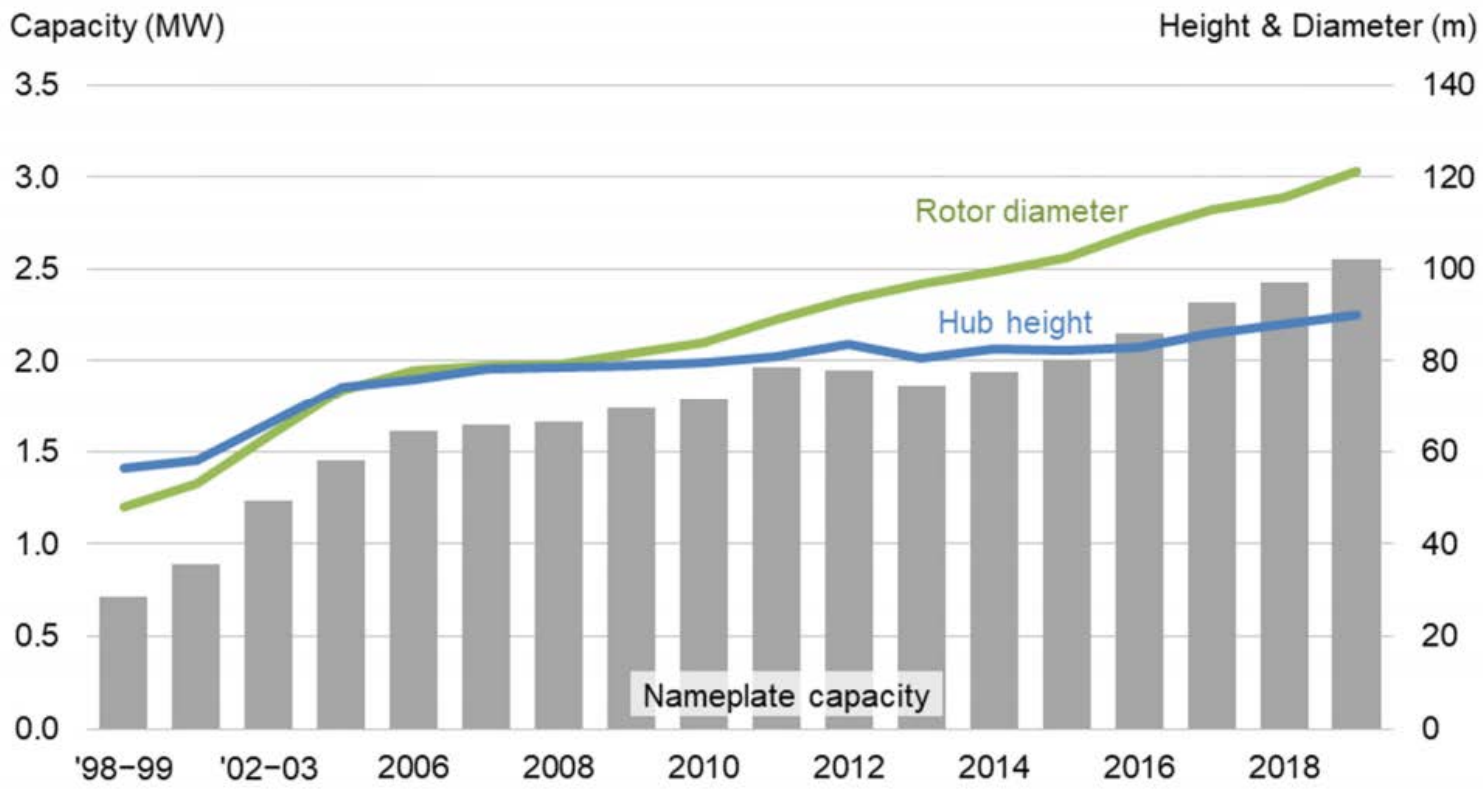

Sources: AWEA Wind IQ, Berkeley Lab

Interactive data visualization: https://emp.lbl.gov/wind-power-technology-trends

Figure 3. The average nameplate capacity, hub height, and rotor diameter for land-based wind from 1998 to 2019. Source: Berkeley Lab (2020)

At the end of 2019, nearly 60,000 wind turbines with a total installed capacity of more than $105,000 \mathrm{MW}$ were located in 41 states, with Texas leading the country in overall installed capacity $(28,871 \mathrm{MW})$ and Iowa having the highest wind energy production as a share of total electricity generation (41.9\%). In addition to the benefits created during the construction of these projects, the American Clean Power Association reports that wind energy supported U.S. communities by paying more than $\$ 1.6$ billion to state and local governments and private landowners every year.

\subsection{State-Level Information}

Each state has wind energy characteristics specific to their state energy profile that shift as new projects are installed and new opportunities, organizations, and research become available. To better understand state wind energy profiles and see specific data, visit the WINDExchange Wind Energy State Information pages, which include:

- Capacity and generation-how much wind energy is produced

- Maps and data — assessing the resource potential of specific areas

- News and events - any specific local and relevant news or events

- Policies and incentives-WINDExchange has an ordinance database that can be searched by state

- Wind education and training - locations of universities and vocational institutions for training opportunities. 


\subsection{Wind Resource Maps}

The ability to assess and characterize a location's available wind resources is critical to the development, siting, and operation of a wind energy project. WINDExchange's collection of wind resource maps illustrates estimates of the wind energy resource across the United States and provides key considerations that must be understood when weighing wind power options. Although these maps can provide a general, high-level indication of wind resources, developers use higher-quality resolutions and more site-specific data that incorporate local features, such as terrain complexities and ground cover. When developers design wind facilities, they supplement this high-level information with measured wind data from the site itself. Still, communities can use high-level wind resource maps to gain a general understanding of the potential for a wind energy project.

A key element of wind energy technology is the turbine height. When using wind resource maps, it is important to consider that the resource potential for an area might change when viewing 80meter $(\mathrm{m})(\sim 262 \mathrm{ft})$ versus 100-m ( 328 ft) maps. In 2019, the average wind turbine had a hub height of $90 \mathrm{~m}(\sim 295 \mathrm{ft})$, but there has been a steady increase in the industry toward projects with tower heights of $100 \mathrm{~m}(\sim 328 \mathrm{ft})$ or higher. This trend has resulted in more than 2,831 wind turbines proposed by the end of 2019, with maximum heights of more than $198 \mathrm{~m}(650 \mathrm{ft})$ (Wiser et al. 2020).

\subsection{Locations of U.S. Wind Farms}

The USWTDB is an interactive map that provides the locations and details (e.g., name, year online, rated capacity, hub height, rotor diameter, total height, turbine manufacturer, and model) of land-based wind turbines in the United States. By zooming into a location, community members or decision makers can identify nearby communities that have wind energy development experience.

As a best practice, learning from multiple expert perspectives and experiences will provide a richer understanding of some of the challenges and opportunities associated with the development process of any industry. Community members can also conduct additional research using the name of a wind energy project to identify the companies that are developing wind energy projects near their community. As with all online research, it is important to be diligent about checking sources and seeking information from trusted, reputable entities.

\subsection{Community Consideration}

Communities and localities across the country are defined by their unique values, physical characteristics, and demographic composition, which influence their vision for land-use planning practices and - therefore-important decisions about renewable energy development projects. Many communities respond in real time to proposals to develop a project in their area. Alternately, communities can be proactive by ensuring their values are reflected in the planning process. Either way, when communities define or redefine their priorities and needs, they should consider the role wind energy may have in achieving their overall goals. Many communities are required to establish comprehensive plans, land-use plans, and/or resource management plans that have sections addressing natural resources, land use, and energy. Including wind energy development in such planning documents can provide rationale for local energy-related decisions and help communities as they work toward defining their energy futures. 


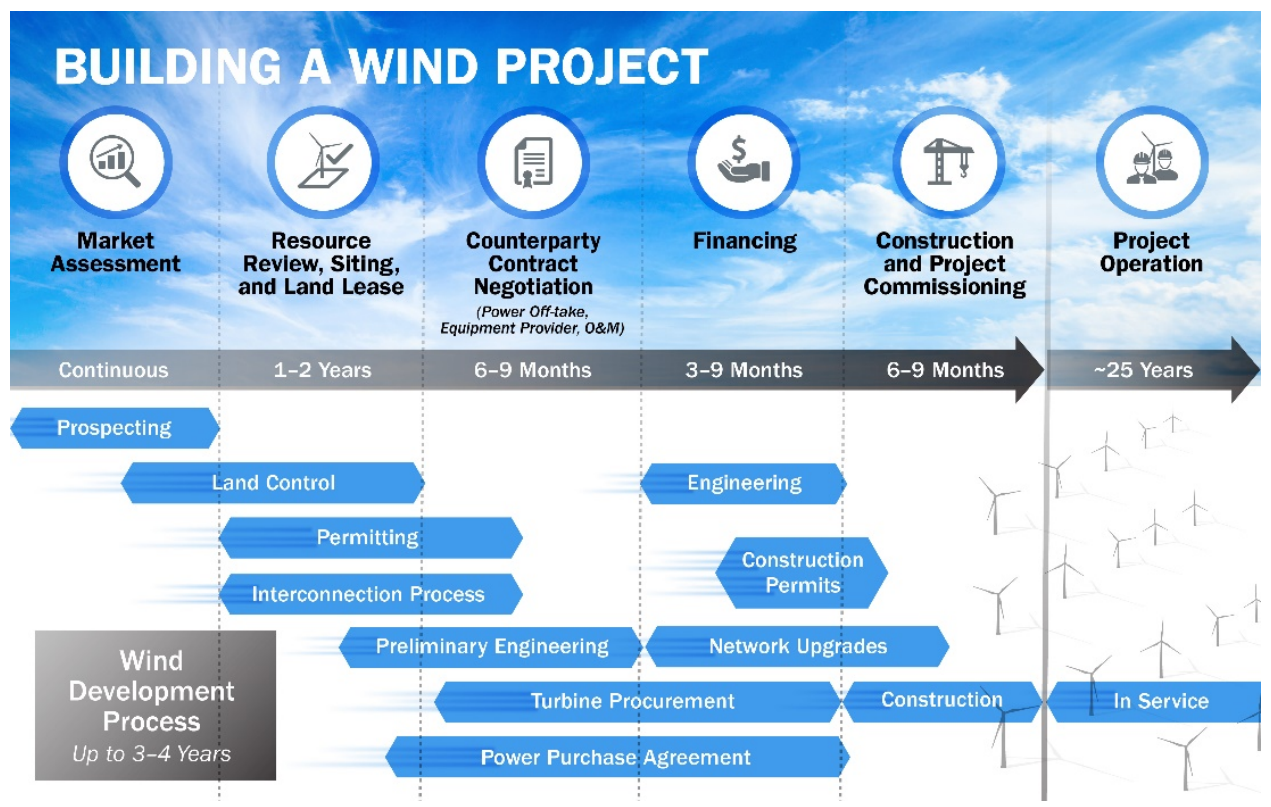

Figure 4. The development of a new wind power plant is a multistep process that can take years to complete. Source: American Clean Power (2020)

\subsection{Project Considerations}

From prospecting through decommissioning, wind energy project development and operations are multistep processes that can span decades (see Figure 4). Project development typically begins with identifying potential locations that have:

- A strong wind energy resource

- Access to electrical markets

- Available and suitable land

- Access to transmission

- Sufficient landowner interest.

Once locations have been preliminarily vetted, developers work with landowners to secure land rights by negotiating lease agreements and conducting thorough wind resource analyses. Other project development activities include studies and processes related to technical, biological, and cultural site assessments; the permit application; grid connection; offtake agreements; and acquiring financial resources. In the context of this guide, an offtake agreement is an arrangement between the developer/owner of a wind energy project and the party buying the energy that the project will produce and deliver over time (O'Melveny \& Myers LLP 2018).

Once project development has advanced sufficiently, engineering, procurement, and construction activities can begin. These activities include detailed engineering and design, procuring wind turbines and other project-related equipment and materials, and constructing and commissioning generation facilities and related infrastructure. Once the operational lifetime of a project is 
complete (25-40 years), the project is either decommissioned 1 or repowered, 2 though repowering can occur earlier if the project owners want to take advantage of new technology and/or available incentives (Wiser and Bolinger 2019b). ${ }^{3}$

\subsection{Regulatory Considerations}

Wind energy projects contain various elements regulated under local, state, or federal hierarchies. Some states require state-level permit approvals, whereas others leave this authority to local governments. Federal regulations apply to all developments in the United States. Federal agency approval is needed for factors such as airspace obstruction, radar and military compatibility, grid interconnection, and impacts to endangered species. Some federal agencies involved include the Federal Energy Regulatory Commission (FERC), U.S. Department of Defense (DOD), Federal Aviation Administration (FAA), and the U.S. Department of the Interior, which includes agencies such as the U.S. Fish and Wildlife Service (USFWS).

Siting authority for a project can rest at the local or state level or both, and it is important for communities to know their state's regulatory jurisdiction. In most areas, the primary siting authority is the local government or a combination of the local government and state regulators (such as a public utilities commission); only four states grant siting authority exclusively to the state: West Virginia, Maryland, North Carolina, and Connecticut. In states with local siting authority, all aspects of siting and permitting a wind project are handled by local government officials, such as township trustees or county commissioners. These communities may need to be aware of additional state approvals that can apply to wind energy projects. States with a hybrid local and state siting authority vary in how their regulations are structured. For example, authority might fall to local governments unless the project reaches a certain size (e.g., $25 \mathrm{MW}$ ); therefore, siting approval may need to be granted to developers by both local governments and state regulators, or state legislation might regulate certain aspects of wind energy projects, such as decommissioning or setbacks. ${ }^{4}$

At the local level, wind energy ordinances are the primary regulatory mechanism, along with appropriate zoning. Ordinances are usually approved by commissioners at the county level, trustees at the township level, or the city council at the municipal level. Wind energy ordinances document local needs, preferences, and safeguards within county or city limits, or in some locations, immediately outside of those jurisdictions. Although many communities might already have a wind energy ordinance, some of these laws may be outdated because of rapidly evolving wind turbine technologies that have been developed during the past decade. Older

\footnotetext{
${ }^{1}$ Decommissioning is the removal of a wind energy project (wind turbines and associated infrastructure) and the restoration of the land that occurs at the end of the project's operational life or at the point when the project is no longer producing power. The length of inactive time that deems a wind turbine to be "not in operation" is often defined in local ordinances or state laws.

${ }^{2}$ Repowering is an alternative to fully decommissioning existing wind turbines. Owners often have the option to repower wind energy projects through a partial repowering or retrofitting that includes replacing older components with new technology or through a full repowering that decommissions the original wind turbines and replaces them with new ones.

${ }^{3}$ Berkeley Lab's Energy I-SPARK website offers more information on incentives.

${ }^{4}$ Setbacks are a required distance from the wind turbine to a designated area of concern, including property lines, inhabited structures (such as homes or office buildings), public roads, project infrastructure, and other specifically identified local interests.
} 
ordinances might need to be updated for current technologies with new siting approaches in mind or they risk being overly restrictive or not restrictive enough. ${ }^{5}$

\subsection{Zoning Considerations}

Zoning is "the division of a city or county by legislative regulations into areas, or zones, that specify allowable uses for real property and size restrictions for buildings within these areas; a program that implements policies of the general plan." Zoning controls actions in certain land-use areas, including whether an individual can install a wind turbine in a particular location after obtaining the proper permits required by state and/or local authorities. Some jurisdictions have defined specific zones (e.g., wind energy overlay districts, renewable energy zones) that limit wind energy development to certain parts of the town/county where the overall impact will be minimal, or in some cases, where the wind resource is best (Oteri 2008). Others set uniform rules across the jurisdiction (e.g., for all properties zoned as agricultural).

\subsection{Economic Considerations}

As with any large-scale infrastructure project, wind energy projects have the potential for economic development because they are capital- and labor-intensive. However, these types of projects also have many unique opportunities and challenges. The way a community might experience economic development from a wind energy project can vary by state, region, and even locality. Counties and other government entities that allow wind energy development in their communities can receive revenue from such developments through taxation, payments, fees, and other compensation. Revenue generated from the development of wind energy projects are used in a variety of ways, depending on the needs and priorities of the local community. More information on economic considerations can be found in the "Land-Based Wind Energy Economic Development Guide."

\subsection{Transmission, Interconnection, and Offtake Agreements}

The U.S. bulk power system - comprising a meshed network of electricity generators, electricity demand, and the transmission infrastructure to deliver the power-is a complex, interconnected machine that is transforming rapidly. Because the grid was originally designed to function with synchronous generators, such as hydropower, fossil fuel, and nuclear, there have been concerns about how incorporating variable energy generators, such as wind and solar, affects grid reliability. Studies have shown that increasing amounts of wind energy can be integrated into the grid without impacting overall power system reliability and that integrating significant levels of wind energy generation (up to 30\%) is both technically possible and economically feasible (Milligan et al. 2015). Grid operators across the United States now have measurable experience in integrating large quantities of renewables into their systems, and wind generation has met electricity demand over time at levels as high as 68.78\% in the Southwest Power Pool in 2019. Detailed planning and operation studies of the power system by grid operators and power system stakeholders analyze what upgrades or changes in operation, if any, are necessary to interconnect wind to the power system. Additionally, wind energy project developers are required to conduct an interconnection study and evaluate any impacts to the existing power system to ensure there are no detrimental

\footnotetext{
5 The National Conference of State Legislatures website offers additional details about state-level approaches to wind energy siting.
} 
effects on grid reliability. Developers analyze the costs of any interconnection upgrades as part of determining overall project viability (Porter et al. 2009).

Transmission is often necessary to connect wind energy generation to load centers. The lead time to build new transmission is longer than the timeline for wind energy project development, making it important to address transmission needs in a timely and coordinated manner at the regional and national levels. New transmission projects can take 5-10 years to plan and build, whereas new wind energy projects can take up to 3 years to build.

A common offtake arrangement for electricity produced by a wind energy project is a long-term contracted sale, most often in the form of a power purchase agreement (PPA). PPAs are contracts between energy producers (such as wind energy project owners) and buyers (such as utilities, corporations, or other large consumers) that specify transaction details, including the price that will be paid for the energy produced. In some cases, the buyer might be located in a state or region that is far from where the energy is produced. The term for these agreements is usually from 10-25 years. Other offtake arrangements include development-transfer or build-transfer agreements with local utilities, merchant offtake arrangements, virtual PPAs (selling power into the grid at wholesale rates with no guaranteed pricing), and financial swaps. ${ }^{6}$

Depending on the amount of wind power produced and the local load and generation, wind energy might be consumed primarily at the local level or within a larger balancing authority area, ${ }^{7}$ or exported to a location where there is demand and need to balance the load. Because of the physical properties of electricity and the transmission grid itself, electricity flows where it is needed on the interconnected grid. ${ }^{8}$

\footnotetext{
${ }^{6}$ Steering committee members assembled the list of offtake arrangements during the review of this guide.

${ }^{7} \mathrm{~A}$ balancing authority area is a collection of generation, transmission, and loads within the metered boundaries of a balancing authority.

${ }^{8}$ Stoel Rives LLP provides a guidebook for business and legal issues associated with wind energy projects. A 2014 white paper from the Eastern Interconnection States' Planning Council provides more detail about transmission planning.
} 


\section{Siting Elements: Considerations, Strategies, and Resources}

\subsection{Construction}

Construction includes the various physical activities that, when completed, result in an operating wind energy project, such as site preparation, component delivery, foundation and wind turbine construction, and site restoration.

\section{Considerations}

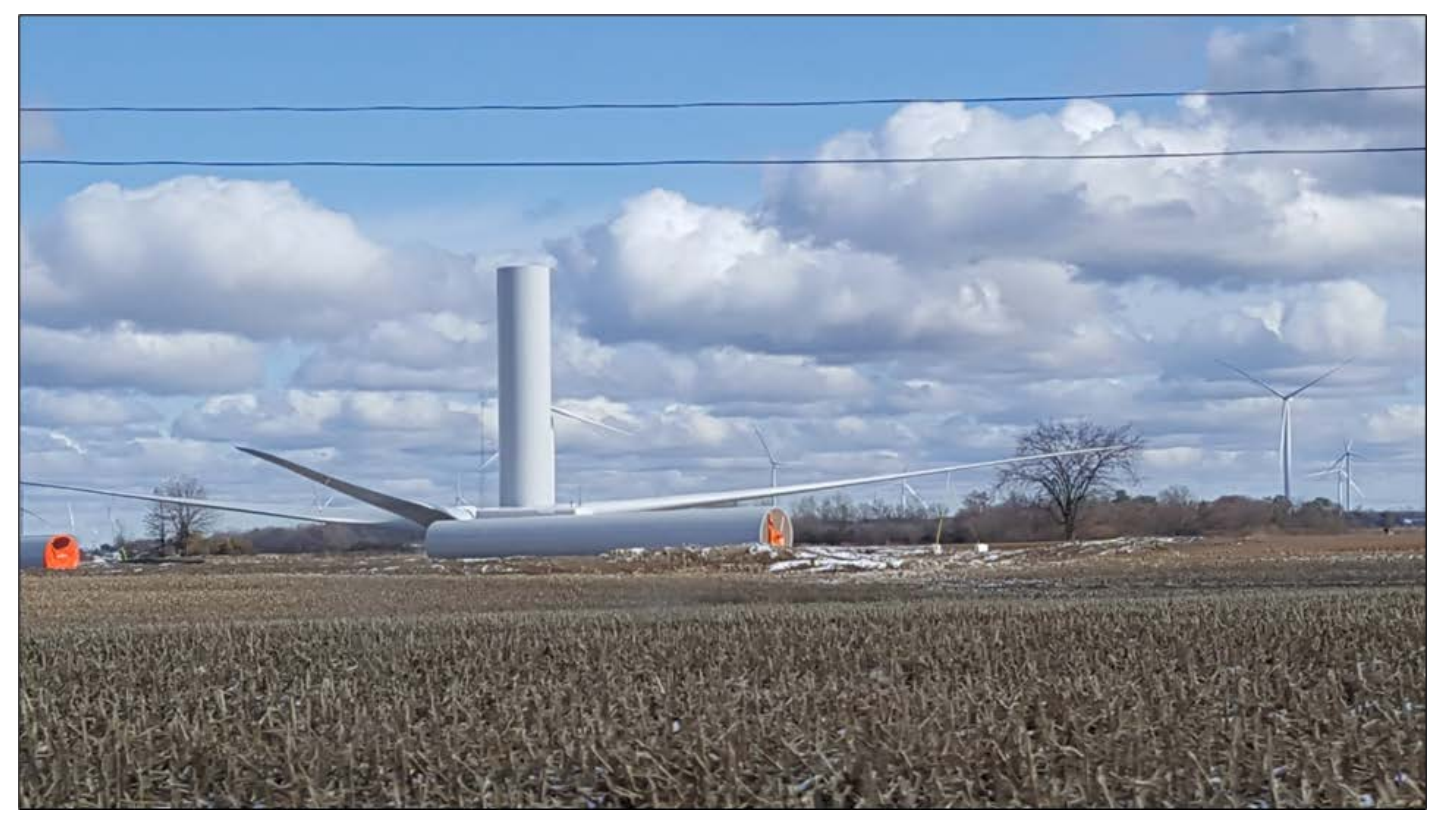

Figure 5. Wind turbine components on agricultural land that will still be used after construction. Photo by Joe Ross

The time it takes to construct a wind energy project depends on project size, multiphase planning, local weather conditions that cause starts and stops, and seasonal severity, particularly in areas with harsh winters. ${ }^{9}$

Project construction generally begins with site preparation, the extent of which depends on the local terrain features and physical characteristics of the individual wind turbine sites. The expected temporary construction disturbance of land for wind energy development is approximately 1.73 acres/MW, whereas the land area expected to be impacted during wind farm operation is approximately 0.74 acre/MW (Denholm et al. 2009). In forested areas, construction could involve removing trees and shrubs that are near or within facility pathways. For agricultural or range land, construction could involve removing some cropland and/or pastureland from production; however, most of the land would remain usable during wind farm operation (see Figure 5). Other early site preparation activities include surveying the site, creating access roads, conducting soil tests, trenching power cables, installing overhead transmission poles, and building out temporary areas for construction yards, office trailers, worker parking, storage, portable sanitation, and waste

\footnotetext{
${ }^{9}$ These variables were identified during discussions with steering committee members.
} 
collection. These activities can require heavy construction equipment (e.g., bulldozers, cranes). In more remote areas, site preparation might also include housing facilities for out-of-state workers (e.g., construction camps, recreational vehicle parks).

Once site preparation is complete, project contractors will begin to deliver wind turbine components (e.g., towers, blades) and excavate turbine foundation sites. Component delivery can damage surrounding road infrastructure. Foundation excavation and construction involve heavy equipment and large amounts of concrete and rebar (see Figure 6). If a project does not feature an on-site concrete batch plant, concrete will need to be transported to the site from local suppliers, thereby potentially creating additional traffic impacts.

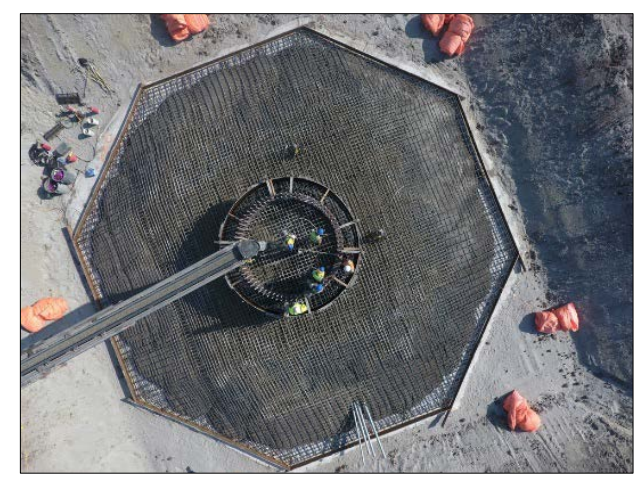

Figure 6. Foundations comprise most of the overall mass of a project when considering wind-turbine- and project-related infrastructure. Photo from Avangrid Renewables, National Renewable Energy Laboratory (NREL) 41780

Once foundations are completed, wind turbine construction primarily involves assembling the components (i.e., first the tower, then the nacelle, ${ }^{10}$ and finally the rotor and blades) (see Figure 7). This process involves using the crane pads and cranes that are assembled on-site to safely lift and place these large components. Because the cranes are large, they typically move ("walk") from one site to another across the project area instead of being disassembled at each wind turbine location. The crane walks can create temporary impacts (e.g., compaction, crop displacement) to the landowner's property and local road infrastructure.

Wind turbines derive their power from rotating blades turning a shaft that spins a series of gears, enabling the generator to create electricity. The electricity is sent down the tower, typically to a transformer, by means of a network of cables or wires called a collector system. The compiled collection of energy converges on a substation, which then collects it and moves it uniformly to a larger transformer. This larger transformer sends the energy to the grid to finally be accessed by consumers. Although most projects feature an underground collector system, the use of overhead or underground cables depends on the location of the wind turbine, local standards that define collector system details, and the characteristics of and potential impacts to the local landscape.

In general, wind energy construction can result in temporary impacts ${ }^{11}$ to a community because of the influx of workers and construction-related activities that can create noise and dust and increase

\footnotetext{
${ }^{10}$ The nacelle sits atop the wind turbine tower and contains the gearbox, low- and high-speed shafts, generator, controller, and brake.

${ }^{11}$ In this guide, the term "impact" is intended to address the physical effects a community might experience during the construction and operation of wind energy development. Communities should consider a variety of other project-
} 
heavy truck traffic and vehicle emissions. Activities to remove and restore roads and other facilities can continue for up to 6 months after the project starts operation (Power Company of Wyoming 2015; County of San Diego 2018).

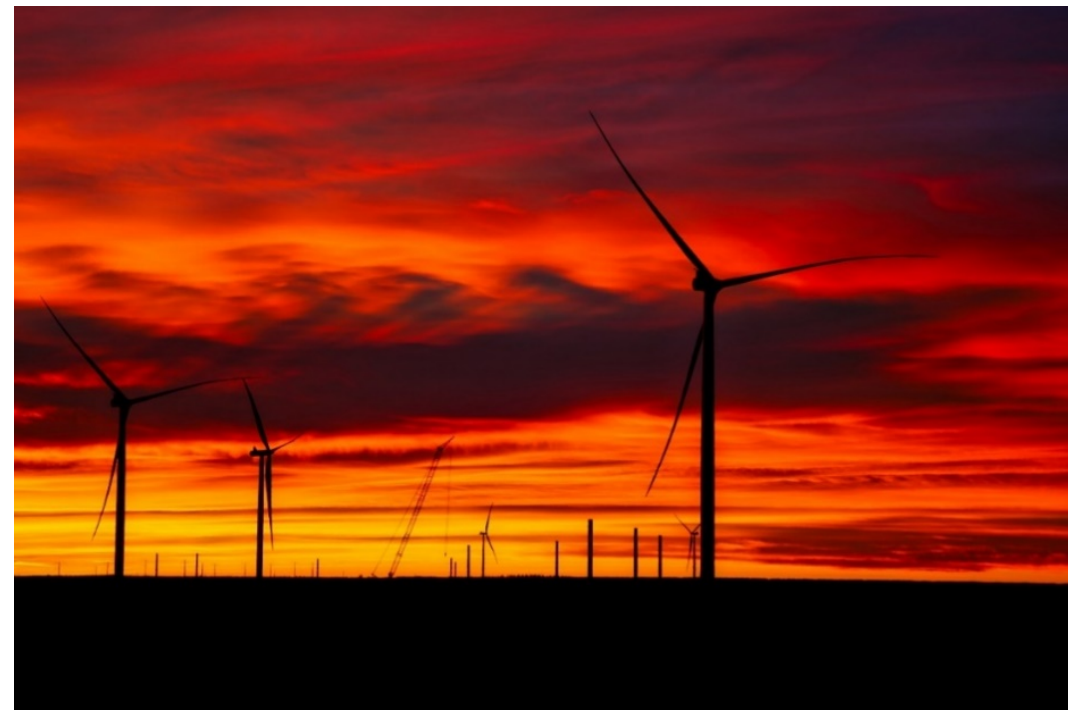

Figure 7. Wind turbine towers (in the background) being erected and attached with blades, nacelles, and hubs. Photo by Dave ladarola

\section{Resources}

For more information on construction, see:

- MidAmerican Energy Company. From the Ground Up: Building Our Energy Future, One Turbine at a Time.

\subsection{Decommissioning}

Removing a wind energy project (e.g., wind turbines and associated infrastructure) and restoring the land could occur at the end of the project's operational life or when a turbine is no longer producing power (e.g., blade, generator, or other component failure from mechanical- or weatherrelated causes like lightning). The length of inactive time that deems a wind turbine to be "not in operation" is often defined in local ordinances or state laws. This process, known as decommissioning, can include removing foundations, access roads, collector lines and substations, and any associated site restoration based on community or state standards, or as agreed upon between the developer and landowner through contractual agreements.

\section{Considerations}

Local regulations and project leases can dictate public and private landowner protections for when the operational life of the wind farm ends or when there are decommissioning responsibilities. Generally, project owners commit to being responsible for the cost of wind turbine disassembly (see Figure 8), off-site disposal, site restoration, and/or recycling of project-related components and

related impacts (positive and negative) when making wind energy development decisions. These impacts can be related to economics, climate, health, water, emissions, and waste. More information on economic impacts can be found in the "Land-Based Wind: Economic Development Guide." 
materials. These commitments are often secured in the form of a bond or letter of credit that is placed after a certain number of years and guarantees that sufficient funds for project decommissioning are available when needed to protect the community and participating landowners. Although most decommissioning plans do not require removing all buried infrastructure, they do require removing all components within an agreed-upon depth to ensure that the project will not interfere with future land use, including agriculture.

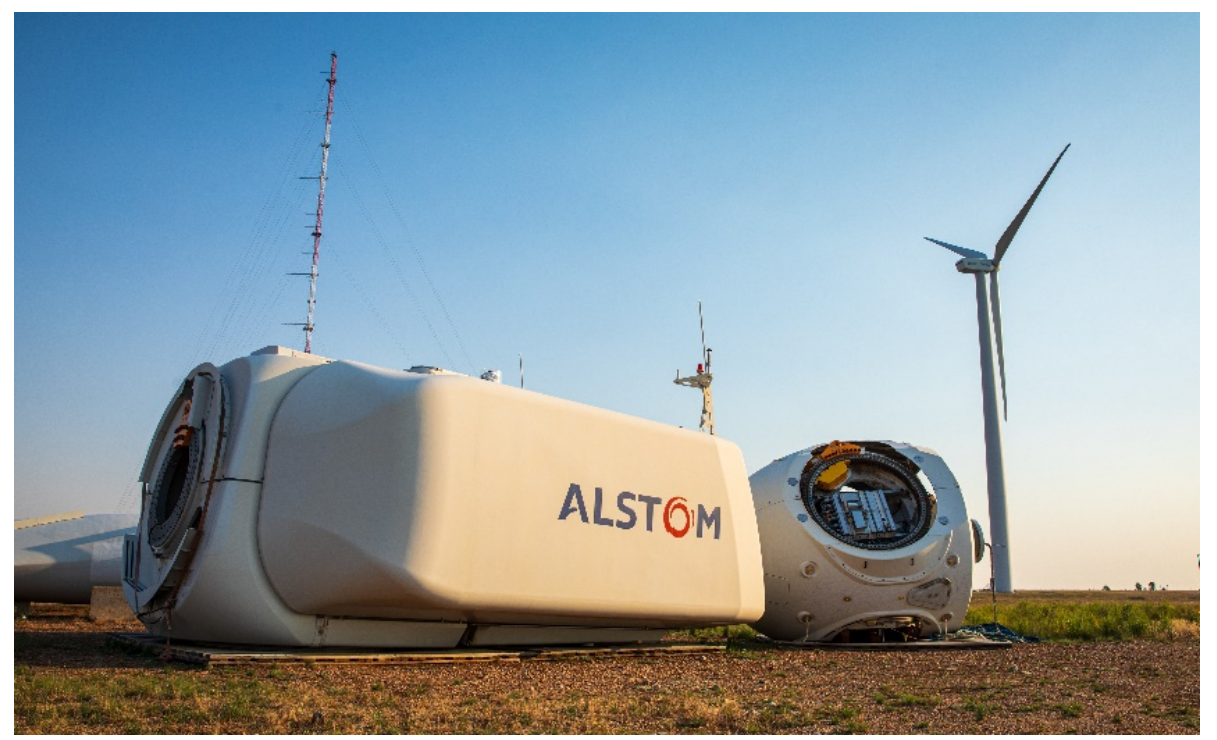

Figure 8. Decommissioned 3-MW GE/Alstom research wind turbine at NREL's Flatirons Campus. Photo by Werner Slocum, NREL 62412

Although wind turbines have an operational expectancy of nearly 30 years (Wiser and Bolinger $2019 \mathrm{~b}$ ), at the end of 2019 less than $5 \%$ of the U.S. wind fleet was 15 years or older, and only 1,054 MW of wind energy had been decommissioned (American Wind Energy Association 2020). As an alternative to fully decommissioning existing wind turbines, project owners often have the option to repower wind energy facilities through a partial repowering or retrofitting that includes replacing older components with new technology or through a full repowering that decommissions the original wind turbines and replaces them with new ones. Partial repowering has historically been incentivized through tax credits, including the production tax credit. The availability of the production tax credit is determined by congressional approval and could impact the number of partial repowers. A choice to fully repower a project might require project developers/owners to complete a new permitting process.

In 2019, 2,803 MW of existing wind energy projects were partially repowered at 30 project sites across eight states - up 129\% from 1,226 MW in 2018. Of the 30 projects, 15 were originally commissioned in 2008, whereas 10 were commissioned in 2009. The average age of partially repowered projects was 11 years (American Wind Energy Association 2020), which was driven mainly by allowing projects to requalify for the production tax credit while improving project performance and extending project lifetime (Wiser and Bolinger 2019a). All partial repowering involved increasing rotor diameters and replacing major internal nacelle components. The new components featured in repowers increase energy production and extend the operational lifetimes of wind turbines (Wiser and Bolinger 2019a). 


\section{Best Practices and Mitigation Strategies}

Lease contracts hold project owners and operation and maintenance (O\&M) technicians responsible for costs related to disassembling, transporting, disposing, and restoring wind energy projects and project sites. Jurisdictional authority (federal, state, or local) for decommissioning depends on the state in which a project is located and who owns the land. Many local jurisdictions add language to their wind energy ordinances to ensure that the decommissioning phase is welldefined. An ordinance can include community-defined decommissioning documentation and assurances that project owners and O\&M technicians must provide to obtain a permit and the standards to which they must adhere during decommissioning.

\section{Infrastructure Removal}

Decommissioning generally involves removing all wind turbines and fully or partially removing related infrastructure. Although a project owner may be required to remove nearly all aboveground infrastructure (e.g., substations, wires, buildings, fencing, and access roads) and restore the land to agreed-upon conditions, many communities choose to define a removal depth that allows some below-ground infrastructure (e.g., foundation and wiring) to remain in place. The agreedupon depth should be deep enough to ensure that the remaining infrastructure does not interfere with future land use, including agriculture. Construction and electrical standards may impact decommissioning requirements. For instance, if a standard requires electrical wiring to be buried at a depth of 48 inches (in.) during construction but the agreed-upon removal depth is 36 in., underground electrical wires would not be removed at the end of project operation. Landowners might agree and negotiate this, among other things, if the underground wiring is at a depth that does not interfere with the property's intended land use.

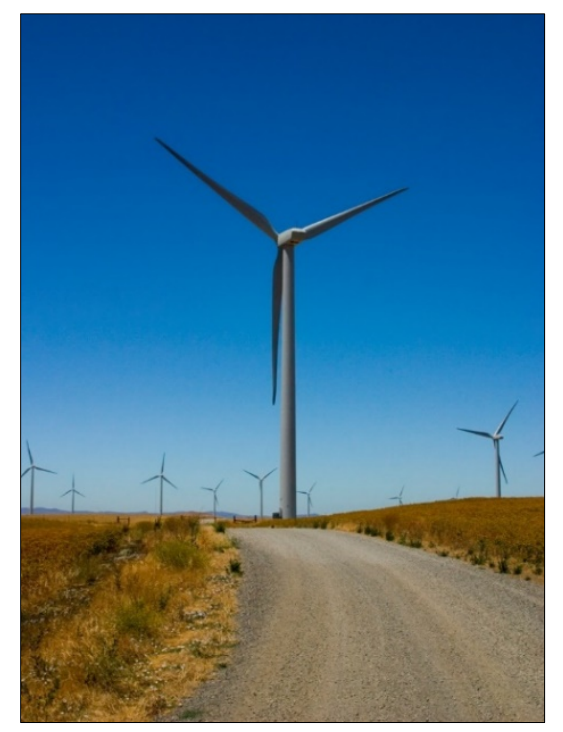

Figure 9. Wind turbine access roads can account for $38 \%-41 \%$ of nonusable land within a wind energy project's footprint (Diffendorfer and Compton 2014). Photo by Dale Carlson

\section{Access Roads}

Access roads to wind turbines usually account for $38 \%-41 \%$ of the disturbed land during the operational lifetime of a wind energy project (see Figure 9) (Diffendorfer and Compton 2014). Although decommissioning requirements can include removing access roads, some landowners 
might decide to keep these private roads on their property, which separates the removal of these roads from the larger decommissioning process. Typically, keeping this infrastructure in place is a landowner request that must be filed with the town/county prior to decommissioning.

\section{Site Restoration}

After wind turbines and related infrastructure are removed, the site is restored as closely as practical to preproject conditions, including decompacting land, reseeding vegetation, and replacing any damaged drainage tiles. For individual landowners, land lease agreements might address compensation options when future crop potential is affected by land compaction or other restoration activities. Wind energy ordinances and/or state regulations have included language to specifically address these concerns and ensure that these elements are part of the decommissioning process. Restoring soil and vegetation might also be addressed in greater detail as part of any environmental language within a wind energy ordinance. The efforts needed to complete site restoration depend on the health of the soil and the volume of on-site construction.

\section{Planning for Decommissioning}

As part of decommissioning practices, many communities require project owners/developers to provide county decision makers with a detailed plan that focuses on the project-specific decommissioning process and defines the activities that will take place to restore the site.

Communities can also require project developers or owners to define the anticipated operational lifetime of a wind energy project. This time frame is usually between 25 and 40 years (Wiser and Bolinger 2019b), depending on wind turbine type and site-specific conditions. Because of the relatively long project lifetime and the potential for component failures, many communities choose to define operational scenarios that trigger the decommissioning process. For example, a community might stipulate that a project or wind turbine be decommissioned if it has not been producing power for a specific amount of time, as defined by local ordinances or state laws (this duration is commonly $9-12+$ months). ${ }^{12}$ Too short of a duration could limit the amount of time for developers to address repairs and accommodate supply chain timelines.

\section{Financial Assurance for Decommissioning}

To ensure that funds will be available to decommission a project at the end of its operational lifetime, state regulations or community ordinances might require project developers or owners to post some form of financial assurance (i.e., a bond, self-guarantee, parent company guarantee, or letter of credit) that will be held until the project is successfully decommissioned, removed, or restored to agreed-upon conditions. These funds will be released once decommissioning is completed to the standards designated in the wind energy ordinance.

Some communities include standards that require a project owner and O\&M technicians to complete decommissioning within a designated time frame. If decommissioning is not completed in a timely manner to community-defined standards, the local government reserves the right to use decommissioning funds at their discretion to remedy these issues.

The total amount covered by financial assurances varies among communities and/or states. Some base this number on the total estimated cost of decommissioning (i.e., cost minus salvage value), whereas others use a designated percentage that is more than the total estimated cost. Other

\footnotetext{
${ }^{12}$ Of ordinances reviewed that included provisions describing triggering events for decommissioning, 53\% indicated they would act after 9-12+ months of not producing power.
} 
communities choose to approach decommissioning costs through a set amount per wind turbine or through a general amount determined by the appropriate authority. Given the operational lifetime of a wind energy project, many communities require updates to decommissioning costs and financial assurances, whereas others require proof of the availability of decommissioning funds. These updates or proof might be required at agreed-upon intervals, at the discretion of the county board, or within some other predetermined time frame. In some cases, financial assurance is not required until the project has been operational for a length of time previously defined by local decision makers and project developers or owners.

\section{Resources}

For more information on decommissioning, see:

- American Clean Power (ACP). Wind Project Decommissioning: Industry Management Practices.

- Energy Policy. "Decommissioning Wind Energy Projects: An Economic and Political Analysis."

- National Renewable Energy Laboratory (NREL). Wind Power Project Repowering: Financial Feasibility, Decisions Drivers, and Supply Chain Effects.

\subsection{Electrical and Power Systems}

Electrical and power systems include the power connection and distribution required for operating a wind energy project, including all wiring and related infrastructure (e.g., substations and transformers). A proposed project can have electrical and power systems impacts on the local grid. If capacity is available, projects can connect to an existing transmission system; otherwise, a new high-voltage transmission line might need to be constructed.

\section{Considerations}

Every wind energy developer must plan and prepare for the power system interconnection as well as the electrical wiring needed within the site. Connecting a wind energy project to the electric grid is a complex process that is typically not regulated at the local level. Upgrades might be required for interconnection, and the cost of making those upgrades usually, but not always, falls on the wind project owner, but it can also fall on the utility. 


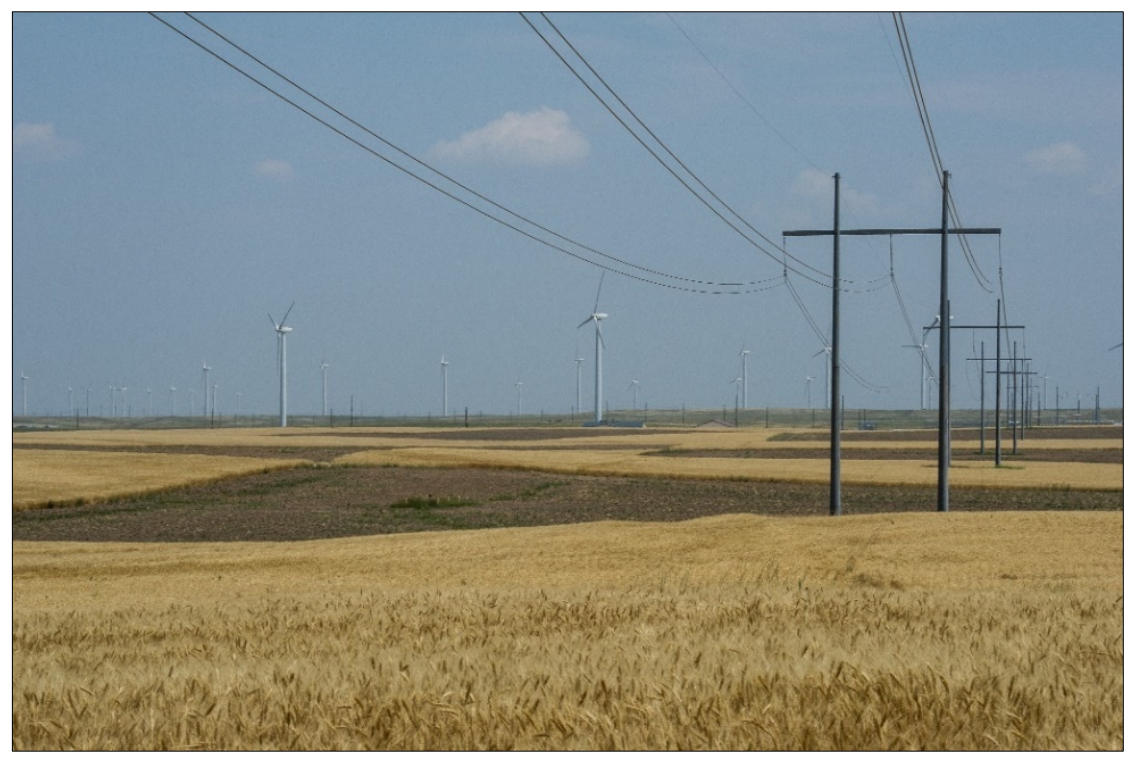

Figure 10. Utility-scale wind turbines and transmission lines at the Cedar Creek Wind Farm in Grover, Colorado. Photo by Dennis Schroeder, NREL 31198

At the federal level, FERC is the decision-making agency that has authority over all interstate and wholesale electricity commerce (FERC 2021). This means that utility-scale wind energy development within any market controlled by a regional transmission operator or independent system operator falls under FERC's jurisdiction. FERC issues interconnection requirements and establishes rules for transmission planning, which are overseen by the regional transmission operator or independent system operator. In other markets, a utility will assume this role, conducting interconnection feasibility studies and issuing interconnection agreements (Chernyakhovskiy et al. 2016). Developers often must invest millions of dollars and should plan for this process to take 2-3 years to determine if a project has viable access to the electricity markets. $^{13}$

Many wind energy developments are sited relatively close to existing transmission lines that have enough capacity for interconnection. As a result, these developments can avoid the added expense and time associated with permitting and constructing high-voltage transmission lines to connect the wind project to the electricity grid (see Figure 10). A project developer or owner might need to build new high-voltage transmission lines to reach the current electric grid but will often aim to minimize such effort because of added costs and regulatory complexity. Wind speed is locationspecific, so developers might have to weigh trade-offs and consider constructing new transmission lines if wind resources are not adequate near existing transmission lines.

Electrical feeder or collector lines connect the wind turbines to a project substation. This mediumvoltage wiring will be constructed by the project developer or owner to collect the electricity generated by the wind turbines and bring it to the interconnection point within the larger transmission network. Communities can dictate where this wiring must be placed, such as below or above ground.

\footnotetext{
${ }^{13}$ More information on electricity markets can be found on the FERC Electric Power Markets page.
} 


\section{Resources}

For more information on electrical and power systems, see:

- U.S. Environmental Protection Agency. "Understanding Electricity Market Frameworks \& Policies."

- Farmer's Guide to Wind Energy. Interconnection and Transmission.

- FERC. "Standard Interconnection Agreements for Wind Energy and Other Alternative Technologies."

- NREL. U.S. Laws and Regulations for Renewable Energy Grid Interconnections.

- Stoel Rives. The Law of the Wind: A Guide to Business and Legal Issues (Chapter 13 Regulatory and Transmission Related Issues).

\subsection{Environment}

The construction, operation, and decommissioning of a wind energy project can affect wildlife (primarily birds and bats) (see Figure 11), habitat, vegetation, water, soil, and more. As a result, some of these concerns are addressed through federal laws, such as the Clean Water Act (CWA), Endangered Species Act (ESA), Bald and Golden Eagle Protection Act, Migratory Bird Treaty Act, National Historic Preservation Act, and the National Environmental Policy Act (NEPA). Other federal, state, or county regulations might also apply.

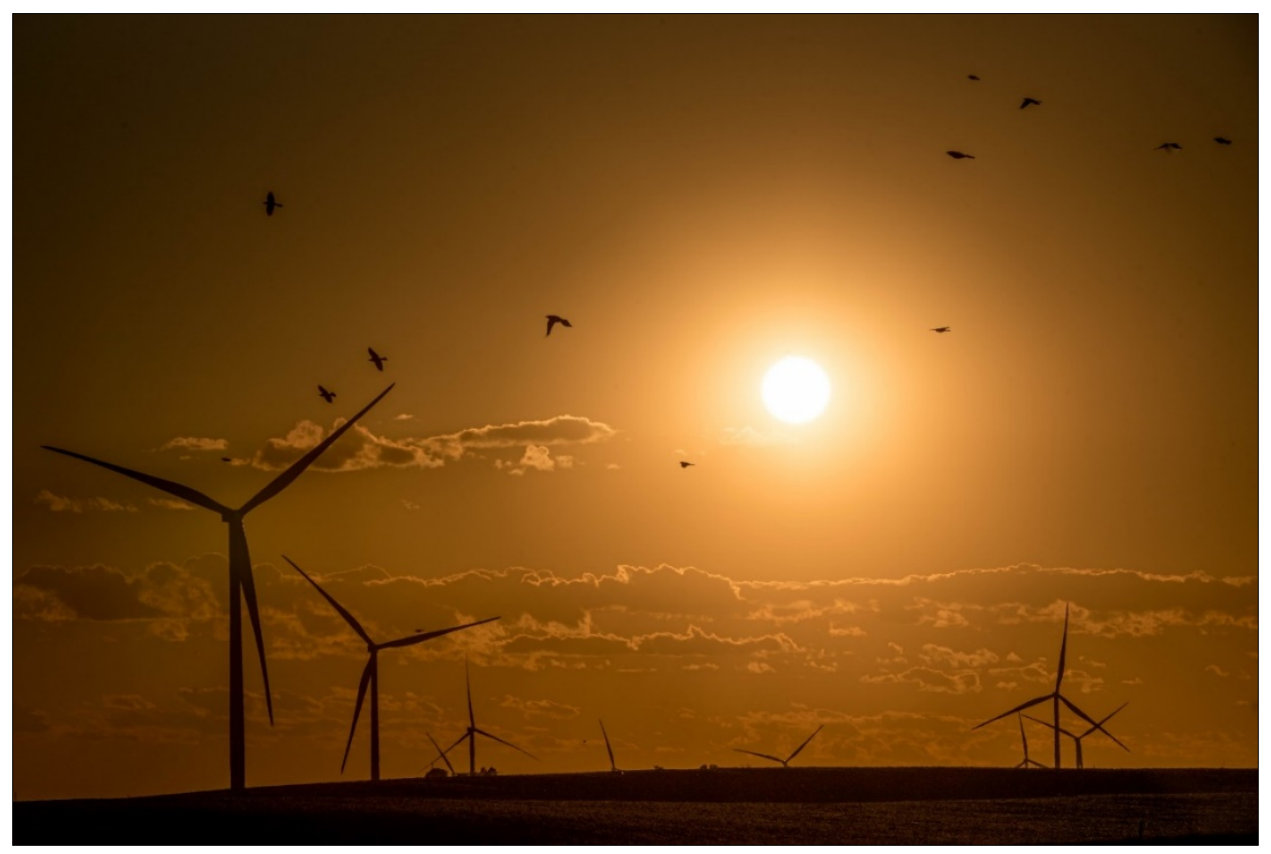

Figure 11. Birds soar through the sky as the sun sets on a wind farm in lowa. Photo by sringsmuth

\section{Considerations}

As with any infrastructure development, wind energy projects can impact the local ecology in a variety of ways. Development can result in direct impacts, such as bat collisions with wind turbine 
blades, or indirect impacts, such as disturbing sage grouse habitat. Because of the unique nature of each site, potential impacts should be assessed on a case-by-case basis. In 2012, the USFWS released the "Land-Based Wind Energy Guidelines." Informed by discussions among the wind energy industry, conservation organizations, regulators, and others, these voluntary guidelines are best practices based on a tiered approach to help developers assess and reduce risk to wildlife from constructing and operating a wind energy facility (American Wind Wildlife Institute undated).

The tiers are:

- Tier 1: Preliminary site evaluation (landscape-scale screening of possible project sites)

- Tier 2: Site characterization (broad characterization of one or more potential project sites)

- Tier 3: Field studies to document site wildlife and habitat and predict project impacts

- Tier 4: Postconstruction studies to estimate impacts

- Tier 5: Other postconstruction studies and research (USFWS 2012).

The guidelines suggest a site- and risk-specific approach that relies on early and regular coordination between developers and agencies to inform decisions regarding preconstruction surveys and postconstruction monitoring of site characteristics and data collected during wind energy development and operation. Additionally, consideration for the frequency and intensity of preconstruction monitoring should be site-specific and determined by consulting with an expert authority who has knowledge of the species, level of risk, and other variables present at each individual site. If a violation occurs following this consultation process, the "[USFWS] Service will consider a developer's documented efforts to communicate with the Service and adhere to the Guidelines" in their decision making (USFWS 2012).

The goals of wildlife impact mitigation efforts are to avoid, minimize, or compensate for the potential effects a wind energy project might have on wildlife. As recommended in the "LandBased Wind Energy Guidelines," preconstruction surveys are used to evaluate potential risk and assess the presence and activity patterns of wildlife at a proposed site before it is built. These surveys can include point counts and nest searches for birds or acoustic monitoring and cave surveys for bats. Postconstruction surveys can validate impact estimates, and in some cases, help determine whether additional mitigation strategies are needed beyond those established during project development. ${ }^{14}$ While birds and bats may be present in a given area, their presence does not dictate mortality rates. For example, some birds and bats might have higher mortality rates than anticipated in the presurvey estimates, whereas others may have less (Erickson et al. 2002). Carcass searches for birds and bats are typically conducted by environmental consulting firms at a subset of wind turbines to develop fatality estimates for the wind energy facility. The take ${ }^{15}$ of a protected species will require consulting with the appropriate regulatory agencies to determine the next steps.

Outside of consulting with the USFWS as noted earlier, federal involvement in wind energy development pertaining to environmental issues can occur through a variety of mechanisms that

\footnotetext{
${ }^{14}$ See Table 3 of the USFWS's “Land-Based Wind Energy Guidelines."

15 The ESA defines take as "to harass, harm, pursue, hunt, shoot, wound, kill, trap, capture or collect, or to attempt to engage in any such conduct." Furthermore, an incidental take is "an unintentional, but not unexpected, taking." (National Oceanic and Atmospheric Administration Fisheries undated).
} 
trigger a "federal nexus." A federal nexus exists for any project that receives federal funding, a federal permit, or other federal authorization that requires a federal agency to ensure that the continued existence of a federally endangered or threatened species is not jeopardized.

Although most wind energy projects will not trigger a federal nexus, those seeking a federal permit will. For instance, projects developing in areas with endangered species can seek permits through Section 7 or Section 10 of the ESA, thereby triggering a federal nexus. Section 7 of the ESA applies to federal agencies taking actions that can affect an endangered species, such as the Bureau of Land Management issuing an energy development permit in an area with a protected species. Consultation typically begins as an informal process but can escalate to a formal action, depending on the findings. A formal consultation typically ends with a biological opinion from USFWS that determines whether a wind energy project will endanger the continued existence of a listed species. If not, the USFWS will issue an incidental take permit ${ }^{16}$ for the project if it is reasonably certain the project will not lead to direct mortalities that endanger the continued existence of a listed species.

Section 10 of the ESA permits apply to development activities that are conducted on private property and may result in "take" of threatened or endangered wildlife (USFWS 2019a). To obtain a permit under Section 10, an applicant must submit a Habitat Conservation Plan (HCP). ${ }^{17}$ Wind energy project owners and developers “... should be advised to develop an HCP and seek an incidental take permit if they are conducting (or planning to conduct) any type of activity in an area where ESA-listed species are known to occur and where their activity or activities are reasonably certain to result in incidental take (USFWS 2021)."

NEPA also applies when there is a federal nexus or "major federal action" (e-CFR 2021), such as seeking to develop a wind energy project on federal or tribal land or interconnecting with federally owned transmission lines. Parties must complete a draft Environmental Assessment or Environmental Impact Statement to be reviewed by the cognizant federal agency. This agency is responsible for authoring the final NEPA document and ensuring that it complies with the Council on Environmental Quality guidance, agency regulations, and existing law. The extent of the project's impact determines the level of required study. For example, where NEPA applies, a project can receive a categorical exclusion ${ }^{18}$; if so, project developers or owners would not need to complete an Environmental Assessment ${ }^{19}$ or Environmental Impact Statement. ${ }^{20}$ Otherwise, a Finding of No Significant Impact (FONSI) demonstrates that an Environmental Impact Statement is not required.

\footnotetext{
${ }^{16}$ An incidental take permit allows the permit holder to legally proceed with an activity that may take a listed species if the take is not the purpose of the activity but is an incidental effect of the activity (USFWS 2019b). ${ }^{17}$ A Habitat Conservation Plan "must specify the impacts that are likely to result from the taking [of a species], the measures the permit applicant will undertake to minimize and mitigate such impacts, and the funding that will be available to implement such measures." (USFWS 2021, Chapter 1).

${ }^{18}$ A categorical exclusion is when "a federal action may be 'categorically excluded' from a detailed environmental analysis when the federal action normally does not have a significant effect on the human environment (40 CFR $1508.1[\mathrm{~d}])$. The reason for the exclusion is generally detailed in NEPA procedures adopted by each federal agency." (EPA 2020).

${ }^{19}$ An Environmental Assessment "determines whether or not a federal action has the potential to cause significant environmental effects. Each federal agency has adopted its own NEPA procedures for the preparation of EAs." (EPA 2020).

${ }^{20}$ An Environmental Impact Statement is prepared by a federal agency "if a proposed major federal action is determined to significantly affect the quality of the human environment." (EPA 2020).
} 
The NEPA process also provides other agencies, stakeholders, and the public with an opportunity to voice concerns and comment about the proposed project and its overall environmental impact (USFWS 2019a).

Although federal regulations address nationally recognized vulnerable or endangered species, some communities can have specific environmental concerns regarding local species and/or habitats not covered by federal regulations. Environmental regulations can also exist at the state level; these regulations and their applicability to wind energy vary considerably among states. Some states have alternative environmental guidelines or regulations solely for wind energy projects, and some require consulting with a state environmental agency. These agencies also vary from one state to another but can include the state's department of fish and wildlife, department of natural resources, or division of wildlife. To avoid jurisdictional confusion, local decision makers should research state-specific details about regulating agencies that address environmental impacts. ${ }^{21}$

\section{Best Practices and Mitigation Strategies}

Community-based solutions to lessen environmental effects depend on the impact being considered, whether existing regulations address the issue, and whether those regulations are at the state or federal level. State and federal rules may supersede local processes, so local decision makers should be aware of applicable state environmental processes to avoid duplicate or conflicting requirements.

Some wind energy ordinances address local environmental concerns by including language that states wind turbines and associated infrastructure will be located in a way that helps minimize impacts to environmental resources. This could be in relation to various ecological factors, including wildlife, habitat, and vegetation.

\section{Prepermit Environmental Analysis and Mitigation Recommendations}

Depending on land ownership, financing requirements, regulating authority, and other issues, a prepermit environmental analysis might be required at the federal, state, or local level. Many project developers consult with state agencies or hire outside experts to perform an environmental analysis for a proposed wind energy project. This analysis can cover a variety of factors (addressed in the considerations/expectations section) but typically includes potential project-related impacts to local wildlife, vegetation, water, and soil. Specific mitigation measures that identify the ways developers will address environmental impacts might also be required as part of this analysis. If state legislation does not regulate the environmental aspects of a wind energy project, language can be included in a local wind energy ordinance mandating that developers conduct further environmental analyses.

Developers can use a completed environmental analysis to help inform project design to avoid or minimize impacts, as feasible. For impacts that are significant and cannot be avoided, developers will usually identify mitigation measures. Specific measures and impacts will vary from one project to another, depending on local environmental conditions.

Mitigation measures can vary in scope and implementation throughout the development and operational processes. Common preconstruction mitigation methods include identifying siting restrictions, restricting removal or degradation of state-protected habitat or federally designated

\footnotetext{
${ }^{21}$ The EPA's Health and Environmental Agencies of U.S. States and Territories list identifies environmental agencies for each state.
} 
critical habitat, implementing worker environmental awareness programs, limiting conversion of certain land types, requiring reclamation and revegetation, and developing erosion control plans. Postconstruction mitigation will depend on a variety of factors relating to which species are present at the site, the preconstruction assessment of risk to those species, mitigation required as part of a permit, or voluntary mitigation. ${ }^{22}$

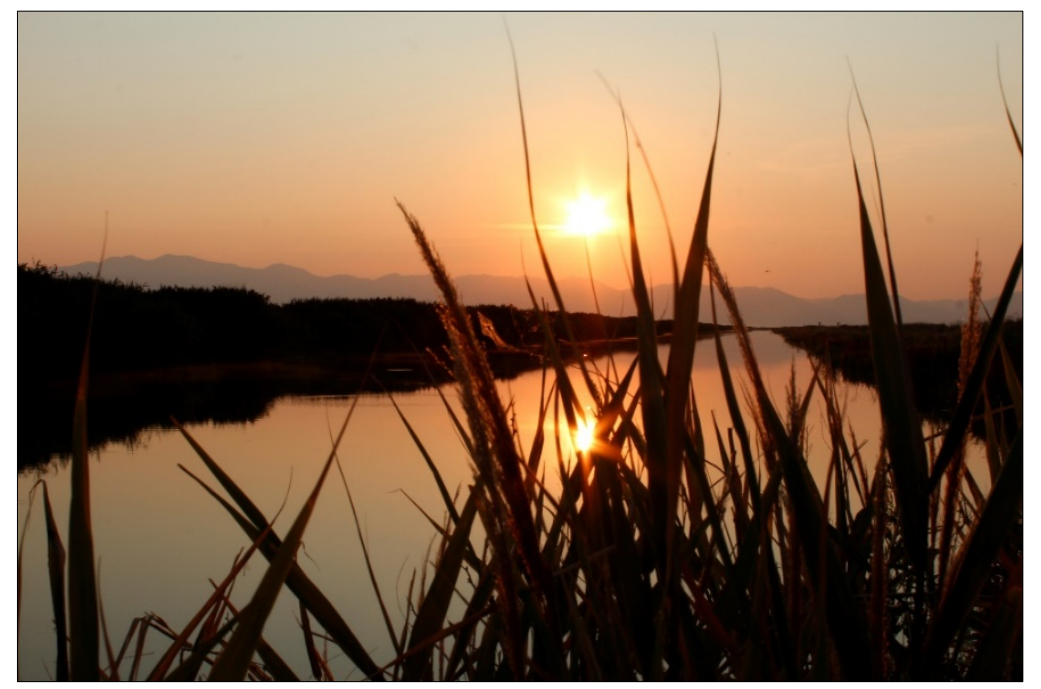

Figure 12. Sunrise at a wetland marsh in Bear River Refuge in Utah. Photo by Jerry Whetstone, USFWS

For bats, one impact mitigation strategy is known as "curtailment" or "blade feathering." This approach limits wind turbine rotor revolutions per minute during certain wind speeds ${ }^{23,24}$ when bats are at greatest risk of collision, such as dusk until dawn during migratory seasons. Another strategy is using ultrasonic acoustic deterrent devices to dissuade bats from entering the airspace around wind turbine blades. For eagles, operators can utilize preconstruction eagle use surveys and nest surveys to site wind turbines away from higher use areas. Another method is to apply informed curtailment to limit operations when eagles are within a risk distance from a turbine, generally 1 kilometer. For other birds, developers can implement best management practices, as described in the USFWS "Land-Based Wind Energy Guidelines."

If there are potentially significant impacts to sensitive or protected species or habitats that cannot be fully addressed by avoidance or minimization efforts, owner/operators may use compensatory

\footnotetext{
${ }^{22}$ More information about adaptive management plans can be found in "Adaptive Management: The U.S. Department of the Interior Technical Guide" (U.S. Department of the Interior 2009).

${ }^{23}$ Feathering turns the wind turbine blades parallel to the wind below cut-in speed to stop the blades from turning and reduce fatalities during moments of high risk. For more information, see American Wind Wildlife Institute's "Bats and Wind Energy: Impacts, Mitigation, and Tradeoffs" (American Wind Wildlife Institute 2018).

${ }^{24}$ Cut-in is the speed at which wind turbines begin producing electricity into the power grid. Most studies found at least a $50 \%$ reduction in bat fatalities when wind turbine cut-in speed was increased by 1.5 meter per second above the manufacturer's cut-in speed (Arnett et al. 2013).
} 
mitigation ${ }^{25}$ to offset impacts, such as purchasing mitigation bank credits ${ }^{26}$ and/or funding on- or off-site habitat enhancements (Hanna et al. 2016). Compensatory mitigation seeks to offset fatalities at a given site by supporting population growth or avoiding fatalities in another, geographically proximate area.

Depending on the type of permit or agreement a developer has with a regulatory body, postconstruction monitoring may be required to verify mortality estimates or the effectiveness of agreed-upon mitigation options. In certain cases, these agreements can include or require adaptive management plans that contain mitigation options designed to lessen impacts to specific species of concern, which are triggered if take of the species exceeds a threshold established during agency consultation. ${ }^{27}$

Environments change and adaptive management plans are a tool typically implemented for state or federally protected species; however, they do not need to address all avian or bat species. Adaptative management plans are negotiated in consultation with state and federal wildlife agencies. If compensatory mitigation is determined to be necessary by the appropriate federal authority, the scope of compensation will depend on the level of impact but also consider measures taken by project developers or owners to promote sustainability in a species, such as protecting bird nesting habitat.

Organizations such as the National Audubon Society are supportive of thoughtfully sited wind energy projects (National Audubon Society 2020). Careful consideration of species presence and local habitat can help inform a wind energy site's risk and facilitate proper siting to lower the overall risk to wildlife. With respect to bats, however, research has shown that preconstruction bat surveys do not predict postconstruction bat presence or mortality. Additional research efforts are needed to better understand the current hypotheses relating to bat behavior across the landscape and around wind turbines (Solick et al. 2020).

\section{Public Engagement in Environmental Review}

Although many environmental policies are regulated at the federal and state levels, there are often ways for communities and individuals to provide feedback on environmental topics of concern. California and New York have modeled state environmental acts after NEPA, receiving comments and input throughout the process from public agencies and interested individuals. In these cases, the environmental analysis can be an informational document to guide the development of appropriate minimization and mitigation measures and give the public and other agencies the opportunity to inform the content.

\section{Permits and Certificates of Compliance}

Siting authority can fall to the local or state level, or both, and it is important for communities to know their state's regulatory jurisdiction. In most areas, the primary siting authority is the local government or a combination of the local government and state regulators, with very few states

\footnotetext{
${ }^{25}$ Compensatory mitigation can be development, restoration, or preservation of core habitat for the species of concern, or offsetting take of the species from another source of mortality. An example is retrofitting power poles for improved species safety (Raptor View Research Institute 2021).

${ }^{26}$ A mitigation bank is a site where wetlands, streams, or riparian areas are restored, established, enhanced, and/or preserved to provide compensatory mitigation for impacts authorized under Section 404 of the Clean Water Act or Section 10 of the Rivers and Harbors Act (USFWS 2019c).

${ }^{27}$ More information about adaptive management plans can be found in "Adaptive Management: The U.S. Department of the Interior Technical Guide" (U.S. Department of the Interior 2009).
} 
(e.g., Connecticut, West Virginia, Maryland, and North Carolina) using exclusive state siting authority. In states with local siting authority, many aspects of siting and permitting for wind energy projects fall to local government officials, such as county commissioners. These communities may need to be aware of additional state and federal approvals, such as environmental policy acts that apply to wind energy. Permits or certificates of compliance may be required because of circumstances such as stormwater runoff or excavation within a floodway or wetland. Per the CWA, one permit that is required for all wind energy projects is the National Pollutant Discharge Elimination System construction stormwater permit, which is a general permit that requires compliance with preset conditions, such as preparing a Stormwater Pollution Prevention Plan. This permit is regulated by the U.S. Environmental Protection Agency but can be granted by the state's environmental regulatory agency.

\section{Environment and Construction Best Practices}

During construction, wind energy developers will implement the considerations and mitigation measures approved in the environmental analysis through federal, state, and/or local government permitting processes. Examples of these mitigation measures include establishing seasonal tree and grassland clearing restrictions, implementing speed limits for construction vehicles, and providing a clear delineation of wetlands and other habitat to avoid disturbance.

To address impacts from vegetation removal and access road construction, communities can mandate a site vegetation removal and restoration plan. In such a plan, developers must state how and when they will restore areas and revegetate them.

Soil compaction might occur during the construction phase and remain after decommissioning. Developers often pay to restore compacted soil postconstruction so it can be returned to agricultural use for the life of the project. If compacted soil cannot support continued agricultural use, some landowner agreements require compensation from project owners/developers for the impacts to their crops until the land returns to its original productive state.

If developers engage in preconstruction planning, they can better place electrical lines ${ }^{28}$ to minimize environmental disruption of ecologically significant habitat to the greatest extent possible, especially if lines are to be buried (which is most common). For example, collection system wiring can be routed around wetlands, woodlands, and native grasslands; if a route around is not practical, project developers can use horizontal drilling to go beneath sensitive areas to avoid impacts.

Communities can also include language in a wind energy ordinance to allow a wind turbine to be re-sited if developers encounter unanticipated environmental circumstances, such as the discovery of critical habitat or sensitive species that violate permit conditions or other federal, state, or local laws. These unexpected circumstances are often identified during preconstruction surveys (e.g., wetlands, biological).

\section{Environment and Decommissioning Standards}

To address environmental concerns during or after the decommissioning process, communities can include requirements in the decommissioning plan outlined within a wind energy ordinance. This plan can mandate site restoration procedures, such as grading and reseeding disturbed areas to the approximate condition prior to wind energy development. In compliance with National Pollutant

\footnotetext{
${ }^{28}$ Electrical lines include feeder lines and collections lines.
} 
Discharge Elimination System permit conditions and stormwater pollution prevention plans, project developers or owners are required to restore sites to minimize erosion after structure removal.

Environment and Setback Limits

Setbacks ${ }^{29}$ are often used to ensure a wind project is a predetermined distance away from ecologically significant resources. They can help protect and preserve conservation areas, wetlands, active and inactive nests, cultural resources, and other local natural areas.

\section{Resources}

For more information on the environment related to wind energy, see:

- ACP. "Wildlife and Windpower."

- American Wind Wildlife Institute.

- Bats and Wind Energy Cooperative.

- National Wind Coordinating Collaborative.

- Natural Heritage Databases (states have their own natural heritage database websites).

- Pacific Northwest National Laboratory. TETHYS.

- Stoel Rives. "The Law of Wind: A Guide to Business and Legal Issues."

- The Nature Conservancy. Site Wind Right map.

- U.S. Environmental Protection Agency. "National Pollutant Discharge Elimination System."

- USFWS.

- USFWS. Environmental Conservation Online System Information for Planning and Consultation.

- USFWS. "Habitat Conservation Plan Handbook."

- USFWS. “Land-Based Wind Energy Guidelines.”

- USFWS. "National Wetlands Inventory."

- USFWS. "Wind Power Siting, Incentives, and Wildlife Guidelines in the United States."

- U.S. Geological Survey (USGS). "Gap Analysis Project.”

- USGS. National Land Cover Database.

- Western Association of Fish and Wildlife Agencies. Crucial Habitat Assessment Tool.

- WINDExchange. "Wildlife Impacts of Wind Energy."

\footnotetext{
${ }^{29}$ Setbacks are the distance between the base of a wind turbine and identified points, such as structures (occupied or unoccupied), property lines, or other boundaries. Setbacks are often measured in distance (miles or feet), a multiplier of the hub height or blade tip, or a combination of both.
} 


\subsection{Land and Airspace Use}

This section discusses the way land and airspace uses interact with wind energy projects. Land uses are land-based activities that take place around a proposed wind project site that involve commercial (e.g., businesses), private (e.g., farms and homes), and public (e.g., recreational [such as snowmobiling] and tourist [such as state and national parks or forests) interests. Airspace uses are the existing aerial activities that take place around a proposed wind energy project that involve commercial, private, military, and rescue aircraft (e.g., airplanes and helicopters).

\section{Considerations}

\section{Land Use}

Though wind energy projects can be spread over large swaths of land that involve several properties across multiple counties and/or townships, the actual project footprint is relatively small once a development is operational. Although there are different ways to define this footprint, approximately $95 \%-99 \%$ of land around and within a wind energy facility can be used for other purposes, such as farming, ranching, or recreational activities (Denholm et al. 2009; Canadian Wind Energy Association undated; Diffendorfer et al. 2019). Land is available for use when there is adequate spacing between wind turbines as well as between various landscape features, as determined by project size, local siting constraints, and landowner negotiations. Additionally, most project-related infrastructure to connect wind turbines (i.e., collection system cabling) is buried at a depth that it is well-suited for continued agricultural use. Given that utility-scale wind energy projects are often sited on agricultural lands, they are highly compatible with many existing agricultural land uses and can even provide revenue for landowners (see Figure 13).

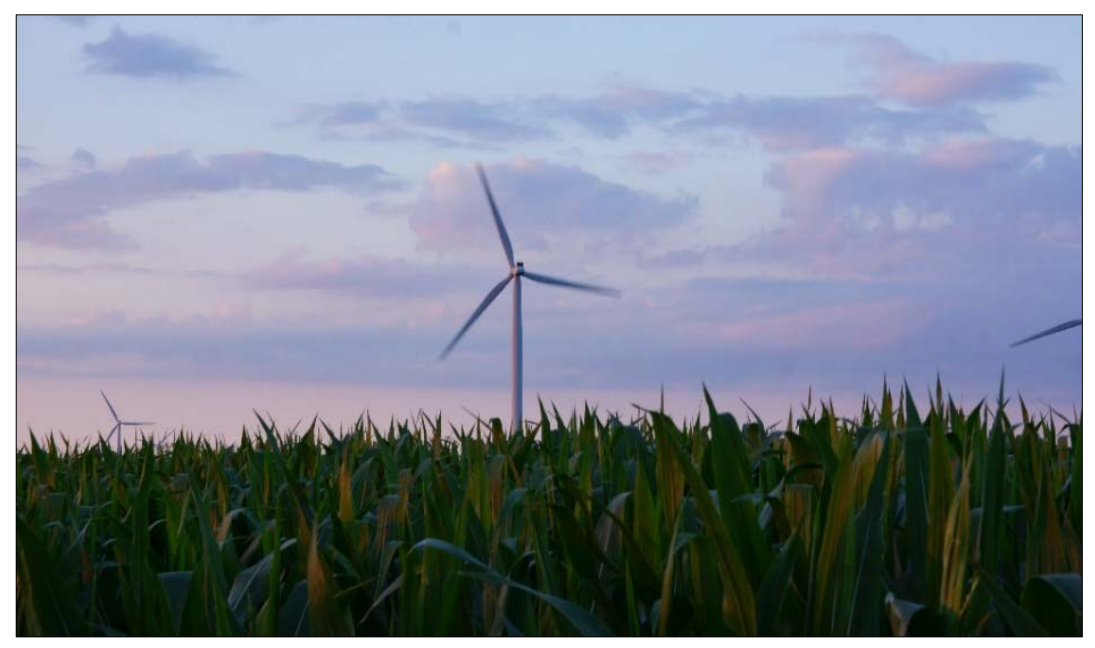

Figure 13. A wind turbine in Indiana located on agricultural land used to grow corn. Photo by Patrick Finnegan

Proposed project sites can sometimes involve sensitive locations that have been designated as scenic corridors or areas with cultural, historical, environmental, or archaeological significance. Land-use impacts for these areas are location-specific and can usually be managed at the local level.

\section{Airspace Use}

Although most aviation activities (including a vast majority related to the military) take place at heights above wind turbines, there are reasons to evaluate the impact wind energy development 
might have on some of these operations. Wind energy projects could affect local airport approach paths, low-level military training, low-level aerial applications for agriculture (commonly referred to as crop-dusting), and emergency medical services (e.g., Flight for Life).

The FAA regulates the installation of all structures taller than $200 \mathrm{ft}$ above ground level by conducting an obstruction evaluation. This process helps identify hazards before a project is built. For wind energy projects, the FAA evaluates and approves the height and location of each wind turbine. If the FAA anticipates potential airspace impacts, it works with the project developer to ensure that all effects are properly mitigated to avoid harm. The FAA process also incorporates formal assessment by other agencies, such as the DOD Mission Compatibility Evaluation Process, which uses the input of all military branches to ensure that military airspace uses are also considered when wind turbine locations are evaluated.

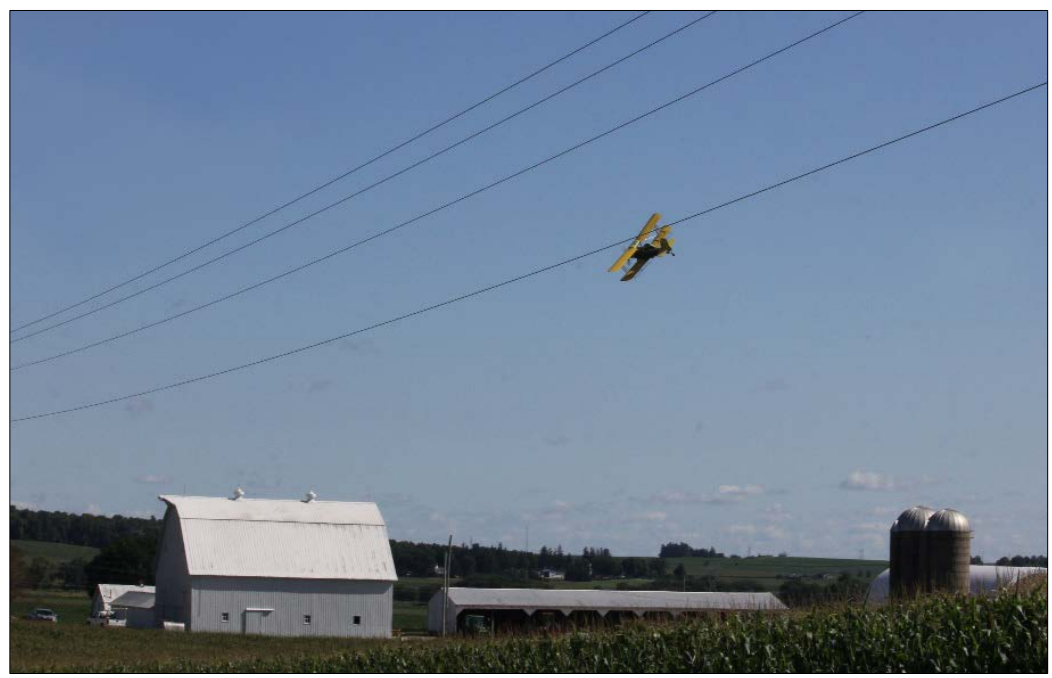

Figure 14. A small plane as it navigates everyday obstructions. Photo by Brad Covington

Aerial applications for agriculture (e.g., fertilizing, applying pesticides) involve low-level flights that are typically conducted 8-10 ft above crops at high speeds (100-120 miles per hour or faster, depending on the type of aircraft) (O'Connor-Marer 2014). These types of flights can be a concern because many wind energy projects are located in rural areas that rely on agriculture as a primary revenue source. Therefore, wind turbines and other project infrastructure (e.g., substations, transmission lines, and meteorological towers) can be considered potential obstructions. Although new infrastructure on the landscape can create challenges for aerial applicators, pilots are usually aware of features like power lines, radio towers, cell towers, or antennae. The FAA issued specific guidance for in-flight surveys that pilots should conduct prior to takeoff so they can understand and identify any obstructions that might interfere with aerial applications for agriculture (FAA 2017). Aerial spraying operations continue in areas where wind energy projects are located (see Figure 14).

Members of some communities wonder whether the presence of wind energy infrastructure could impact emergency medical flights. According to Flight for Life, aerial emergency medical transport services generally consider wind turbines to be no different than other obstructions that are already prevalent, including power lines, utility poles, large signs, and cell towers. These types of infrastructure can be safely avoided without interrupting essential services (Flight for Life 
undated).$^{30}$ Some communities have language within their wind energy ordinances requiring project developers or owners to register the locations of wind turbines and related infrastructure with local emergency services during the permitting process. ${ }^{31}$

\section{Resources}

For more information on land and airspace use, see:

- DOD. "Military Aviation and Installation Assurance Siting Clearinghouse: Mission Compatibility Evaluation Process."

- FAA. "Obstruction Evaluation/Airport Airspace Analysis."

- FAA. "Wind Turbine FAQs."

- NREL. "Land-Use Requirements of Modern Wind Power Plants in the United States."

\subsection{Property Value}

This section outlines changes to the value of real estate in proximity to or within view of a wind energy project (see Figure 15) because of the construction or presence of that facility.

\section{Considerations}

The construction of any new development — renewable energy or otherwise - can cause concern among nearby property owners who may wonder whether the project will have a negative monetary impact on their individual investments. The following section discusses several studies that examined large samples of home sales around wind energy facilities to determine whether these facilities impacted nearby property values. These studies have repeatedly concluded that wind energy development has had minimal impact on nearby home property values in the United States.

\footnotetext{
${ }^{30}$ Coordination with emergency services was required in approximately $10 \%$ of the ordinances reviewed.

${ }^{31}$ Although emergency weather- and other radar-related concerns could be considered as part of land/airspace use, for this document they are included in Section 2.10.
} 


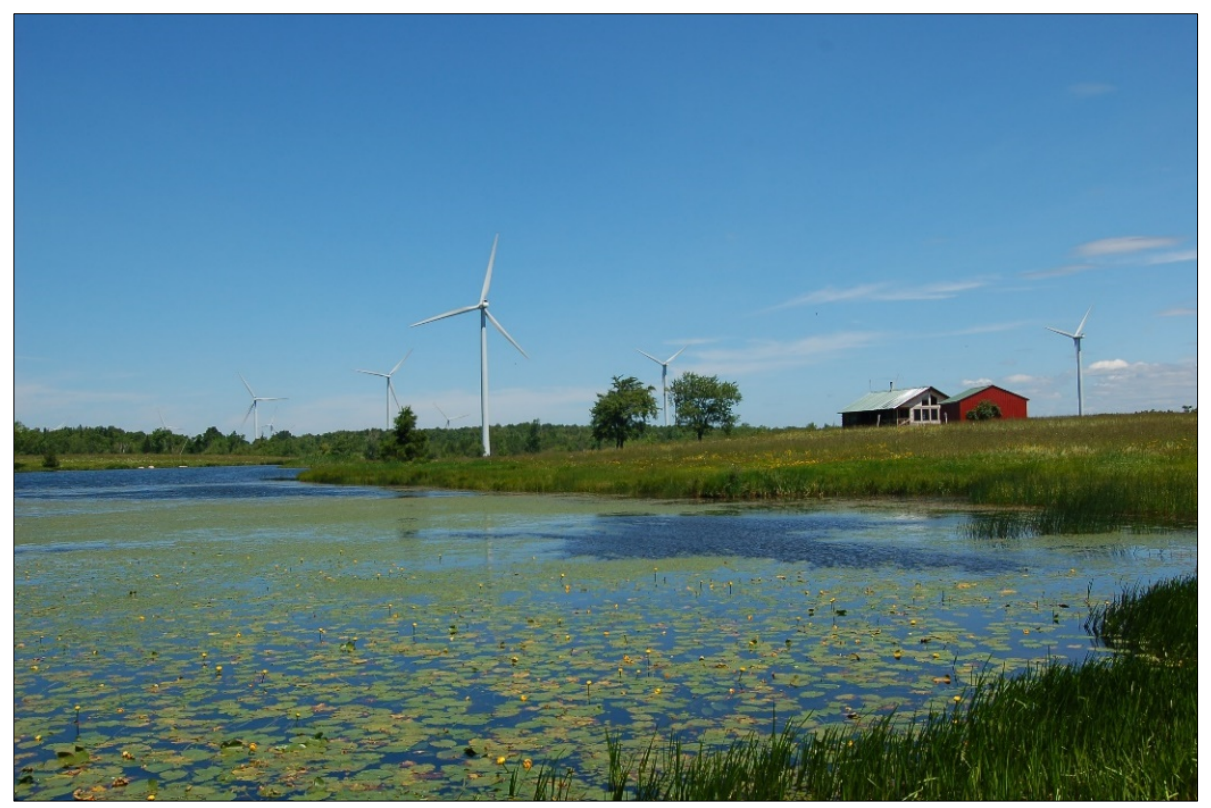

Figure 15. Wind turbines in Lowville, New York, located near existing structures and a pond. Photo by Mark Plummer

Concerns about potential devaluation of a piece of property because of wind energy development tend to be related to whether the project can be seen, whether the property is adversely impacted by the project in other ways, and whether the project will make the surrounding area seem more developed (Hoen et al. 2011).

Berkeley Lab conducted in-depth analyses in 2009 and 2013 regarding wind energy impacts on property values. The 2009 study analyzed data on almost 7,500 sales of single-family homes situated within 10 miles of 24 existing wind energy facilities in nine U.S. states. Findings indicated that if property value impacts existed, they were too small and/or too infrequent to result in any widespread, statistically observable impact, although the possibility that individual homes or small numbers of homes had been or could be negatively impacted could not be dismissed (Hoen et al. 2009). The 2013 study analyzed more than 50,000 home sales near 67 wind energy facilities in 27 counties across nine U.S. states and found no impacts to nearby home property values (Hoen et al. 2013).

\section{Resources}

For more information on property values, see:

- Berkeley Lab. "A Spatial Hedonic Analysis of the Effects of Wind Energy Facilities on Surrounding Property Values in the United States."

- Berkeley Lab. "The Impact of Wind Power Projects on Residential Property Values in the United States: A Multi-Site Hedonic Analysis." 


\subsection{Road Use and Maintenance}

This section discusses concerns about the impacts to existing public roads and accompanying infrastructure during the staging and construction of a wind energy project as well as the planning and construction of related access roads.

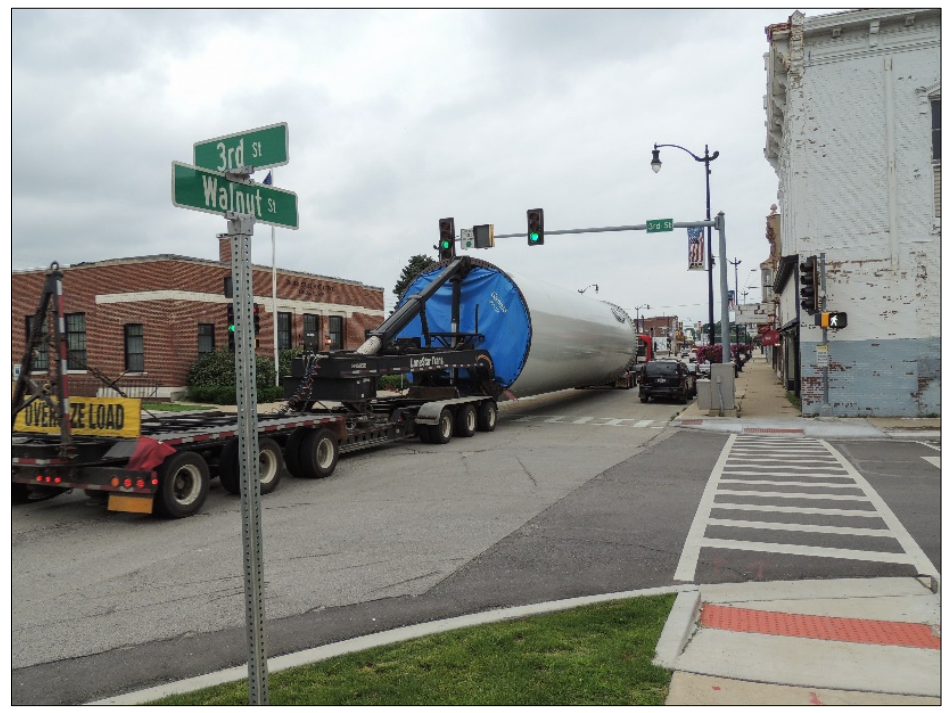

Figure 16. A wind turbine tower being transported through an Illinois town. Photo by risingthermals

\section{Considerations}

Considering how the construction of wind energy projects will impact public roads and access roads is important. Public road concerns are primarily related to the staging and construction phases of a wind energy project when oversized trucks transport wind turbine components and other project-related materials to the site (see Figure 16). The large size of many wind turbine components and the limitations of some rural roadways create the potential for damages that could require repair, postconstruction rehabilitation, or potential closure that could impact traffic patterns during certain times of year (e.g., agricultural harvest). Additionally, some intersections will need to be temporarily widened to accommodate the large turning radius of vehicles transporting wind turbine components to the site. Developers often negotiate road use agreements with local governments to address the use, upgrades (if necessary), and postconstruction repairs (if necessary) of public roads (André et al. 2006). Once projects are operational, they generate minimal additional traffic on local roads.

Access roads are necessary to reach each wind turbine or associated infrastructure and are located on private property. Although it is possible that existing roads on participating landowners' properties can be used, it is much more likely that new roads will need to be constructed (see Figure 17). While originally used for transporting the equipment for wind turbine construction, these roads and access points will need to be maintained for the life of the project so that O\&M technicians can continue to have access. The landowners also have access to the roads on their property, which can be helpful for farming or ranching operations. Access roads can potentially impact the current land usage at a given site, so landowners should work toward having consistent and transparent communication with project developers/owners to understand and lessen potential impacts, especially because wind turbine locations and access road siting could change during the planning process. Additionally, developers often need to obtain administrative permits from the 
local government to ensure that access road entrances to public roads are in appropriate locations that consider factors such as sight lines and water flow in ditches.

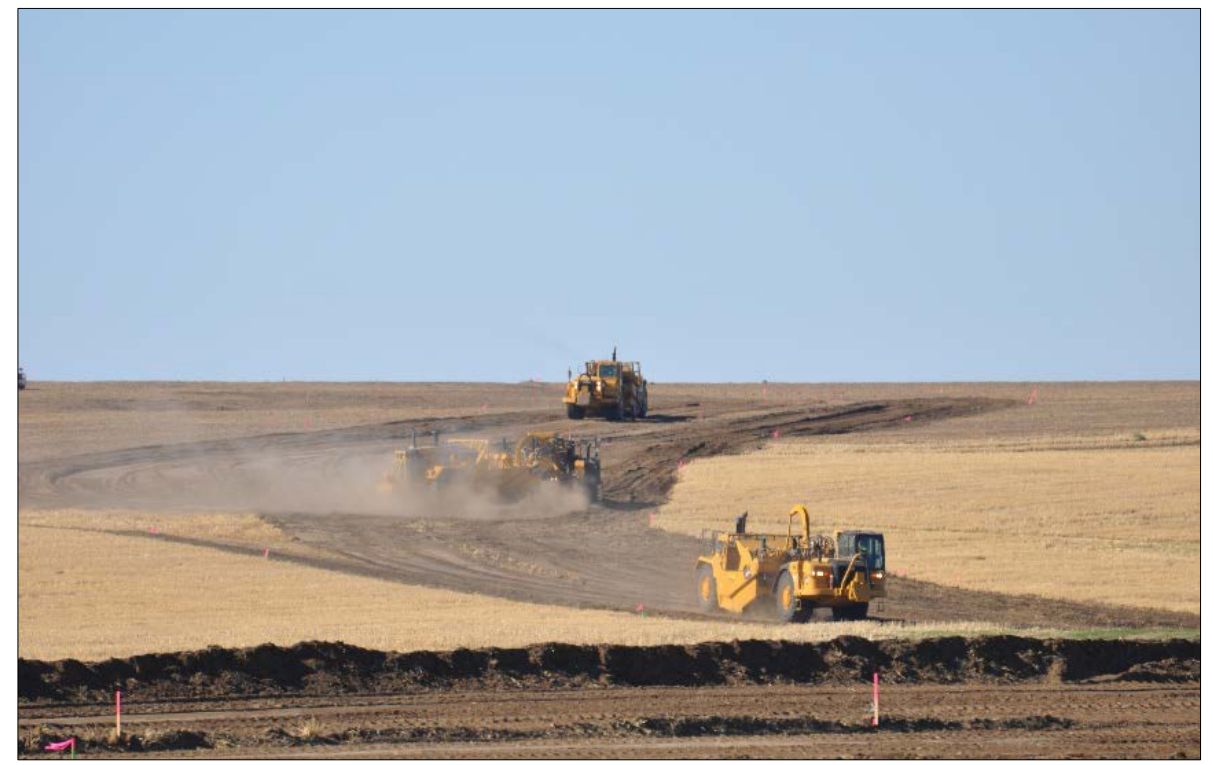

Figure 17. The construction of access roads for the Tucannon River Wind Farm near Dayton, Washington. Photo from Portland General Electric

\section{Resources}

For more information on road use and maintenance, see:

- Energy Trust of Oregon. "Community Wind: An Oregon Guidebook."

- NREL. "Transportation of Large Wind Components: A Permitting and Regulatory Review."

- NREL. "Transportation of Large Wind Components: A Review of Existing Geospatial Data."

\subsection{Safety}

This section discusses minimum standards used to protect individuals and communities from project-related hazards or other potentially harmful outcomes during wind energy project construction and operation.

\section{Considerations}

With more than 67,000 wind turbines operating across the United States (USGS undated), wind energy represents a large capital investment by private companies and financiers. Returns on these investments require consistent production whenever the wind is blowing, so projects are held to high design standards and O\&M procedures to keep wind turbines operational. Having safety procedures that focus on wind turbine reliability is also essential to ensuring that wind projects are ready to contribute to U.S. energy needs. 
Safety regulations can help ensure that:

- The design and construction of wind energy projects meet structural specifications.

- Individual investments (such as homes or other structures) are protected.

- Facilities are properly lit during nighttime operations.

- Emergency procedures are properly implemented to prepare local resources for worstcase scenarios.

Typically, worst-case scenarios are thought of in terms of catastrophic failures (e.g., wind turbine blade failure, turbine collapse, nacelle fire), even though the probability of injury or property damage from these events is extremely low. To avoid wind turbine failures, wind energy project developers and owners place high priority on regular maintenance, which can help reduce the chance of failure. Wind turbines are equipped with sensors and data acquisition systems designed to turn the turbine off when any unusual operational condition occurs - and typically before a catastrophic failure.

Additionally, wind turbine foundation and tower design requirements help ensure the structural integrity of wind turbine components and the general safe deployment of this clean energy resource.

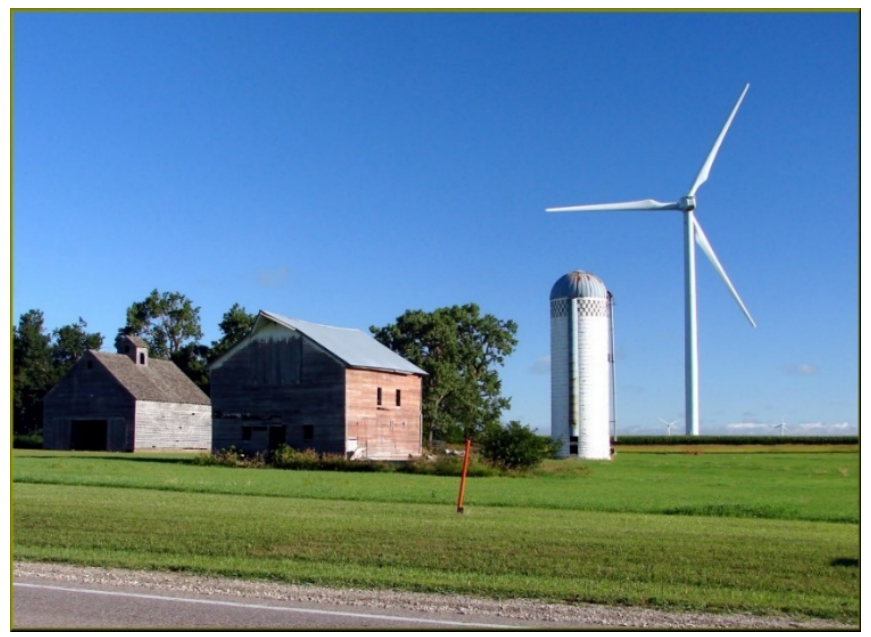

Figure 18. A wind turbine setback from farm buildings in rural lowa. Photo by Don Graham

In general, certain minimum setbacks are maintained between wind turbines and structures (see Figure 18), roads, property lines, and other local features to protect nearby structures and residents from catastrophic failures and other operational risks, such as ice drop ${ }^{32}$ (New York State Energy Research and Development Authority [NYSERDA] 2017). In these types of conditions, additional technology options (e.g., de-icing and anti-icing systems) are available that prevent the likelihood of ice drop.

Additional community safeguards can include minimal blade-clearance requirements and measures to limit access to and prevent unauthorized climbing of towers. Federal safety standards can also require project developers or owners to display multilingual signs that identify other safety risks and procedures.

\footnotetext{
${ }^{32}$ Ice drop is the release of accumulated ice on a wind turbine blade after a freezing event and is relevant primarily in cold weather communities and areas with robust winters.
} 
Nighttime lighting requirements, regulated by the FAA, are important to ensure the continued safe operation of commercial, private, military, and rescue aircraft. FAA regulations require synchronized red lights at the top of a wind turbine (one light for turbines $499 \mathrm{ft}$ tall or less and two for turbines $500 \mathrm{ft}$ or taller), with no unlit turbine separations or gaps of more than a half mile. Wind turbines taller than $699 \mathrm{ft}$ are required to have three midtower lights, as well as two top lights (FAA 2015).

In 2016, a new advancement in nighttime lighting was approved by the FAA (FAA 2016) aircraft detection lighting systems (ADLS) — which limit nighttime lighting of wind turbines when aircraft are not present. Any use of these types of systems must be reviewed and approved by the FAA and included in the initial FAA notice of filing. Additionally, the lighting system must be manufactured by an FAA-approved vendor. Wind turbines are required to have lighting but are not required to be lit constantly if they have an ADLS. Other mitigation technologies or plans might be more applicable if the FAA does not approve using the ADLS. In 2017, North Dakota enacted HB 1378, a law that required wind energy projects to use these systems statewide (North Dakota Legislative Council 2021). Similar language has been included in county ordinances outside of North Dakota to require project developers/owners to use or pursue use of this type of lighting system.

To ensure local preparedness, in some areas wind energy project developers and owners are required to establish safety procedures that define local response to emergency scenarios involving a wind energy project, its workers, and the larger community. These procedures can include communicating regularly with local emergency responders, conducting mutual training activities, and implementing address signs at access road entrances for easy identification by first responders. Some areas require formally filing these plans with local officials, whereas others leave it to the project operators to manage. Emergency response plans are very detailed, and it is important that local governments do not ask for this information too early as emergency response plans cannot be produced until the wind turbines are selected and the layout is finalized.

\section{Best Practices and Mitigation Strategies}

In areas that view wind energy as a compatible development, project developers, owners, and communities desire a project that will operate safely in the long term. Some communities have included specific language within their wind energy ordinances to reinforce this aim by focusing on applicable design and building requirements, component requirements, and compliance certification. Much of the information related to wind energy safety requirements is uniquely technical and complex, so related ordinances should be developed under the guidance of subjectmatter experts.

\section{Applicable Design and Building Requirements}

In ordinances related to design and building requirements, communities can direct project developers toward existing standards and codes, including those developed by the wind energy industry or other outside organizations. Though most project developers and owners voluntarily follow such standards, some communities might specify this guidance to ensure the structural integrity of wind turbine components and safe wind energy deployment. 


\section{Component Requirements}

Some communities might include safeguards related to specific project components with the intent of preventing equipment failure. To address braking system requirements, some communities included redundancies, ${ }^{33}$ specific brake types, additional controls, and any mandated component documentation within their ordinances. To address blade imbalance thresholds, which might be exceeded with ice buildup, some ordinances require projects to use blade components that are designed to withstand a specific percentage or amount of added weight. Other communities require wind turbines to include grounding equipment that protects wind turbine components from damage and potential catastrophic failure during electrical storms. Additionally, communities might mandate that projects feature wind turbines with a threshold that can withstand high-wind events.

\section{Compliance Certifications}

Some community ordinances use compliance certifications to verify the design of certain wind turbine elements. These certifications are used primarily to confirm that the turbine design meets manufacturer standards or that the foundation and tower have been designed within standards specific to local soil and climate. These certifications are usually provided by third-party engineers.

\section{Additional Community Safeguards}

Other community safeguards have been used to ensure public safety, such as rules intended to create public awareness and limit public access related to potential project hazards. Common examples of additional community safeguards include:

- Signs. Signs include multilingual postings that identify high-voltage warnings, disconnection procedures, emergency contact information, no-trespassing notices, fallingice warnings, wind turbine identification, guy-wire ${ }^{34}$ identification, and aviation warnings.

- Access prevention. Access prevention can include, but is not limited to, exterior climbing and ladder requirements, fencing requirements for the substation and projectrelated infrastructure, and service door locking procedures (see Figure 19).

- Hazardous materials. Safeguarding against issues with hazardous material storage and waste procedures might involve including language that dictates jurisdictional criteria of disposal and other general standards.

- Ice drop. Counties might require wind energy project developers or owners to include reports that calculate the maximum ice drop distance and methods to detect blade icing. Further, wind turbine packages are available to prevent ice drop from occurring.

- Blade clearance. Wind turbine blade clearance is a community-defined minimum distance between the ground and lowest possible wind turbine blade position that is intended to create adequate space for safe operations. Though some wind energy

\footnotetext{
${ }^{33}$ Component redundancies are a design strategy often used to improve the reliability and availability of wind turbine systems in the event of a failure. These benefits are achieved by adding one or more components of the same type that operate in parallel (e.g., sensors), aiming to increase the probability of maintaining performance until maintenance can be performed (Echavarria et al. 2012).

${ }^{34}$ In utility-scale wind energy projects, guy wires are typically used to support and stabilize anemometer towers.
} 
ordinances require a blade clearance of $85 \mathrm{ft}$ or less, the average blade clearance for wind turbines installed in 2019 was $96.8 \mathrm{ft}(29.5 \mathrm{~m}){ }^{35}$

\section{Lighting Requirements}

As previously discussed, nighttime lighting requirements are important to ensure the continued safe operation of commercial, private, military, and rescue aircraft.

An additional safety-related lighting concern involves accessory structures (i.e., O\&M building, substations, and gates). Lighting for this form of project infrastructure can be defined in ordinances and typically includes hooded/downward shielded, timed, and/or motion-detected sensors to minimize potential for light pollution.

\section{Safety and Setbacks}

Community-defined setbacks are a required distance from the wind turbine to a designated area of concern, including property lines, homes, businesses, public roads, project infrastructure, and other identified local interests. The defined setback within an ordinance helps create a buffer that supports safe operation and reduces the risk of impact from a catastrophic failure (e.g., wind turbine blade failure, wind turbine collapse, nacelle fire) or other noncatastrophic occurrences, such as ice drop (see Figure 20). Setbacks vary depending on a variety of community factors, including current land use, population density, and general compatibility. Even in areas where landowners waive their rights to established setbacks via an agreement with the wind project developer, many communities require wind turbines to be spaced at least 1.1 times the height of the turbine from the area of concern.

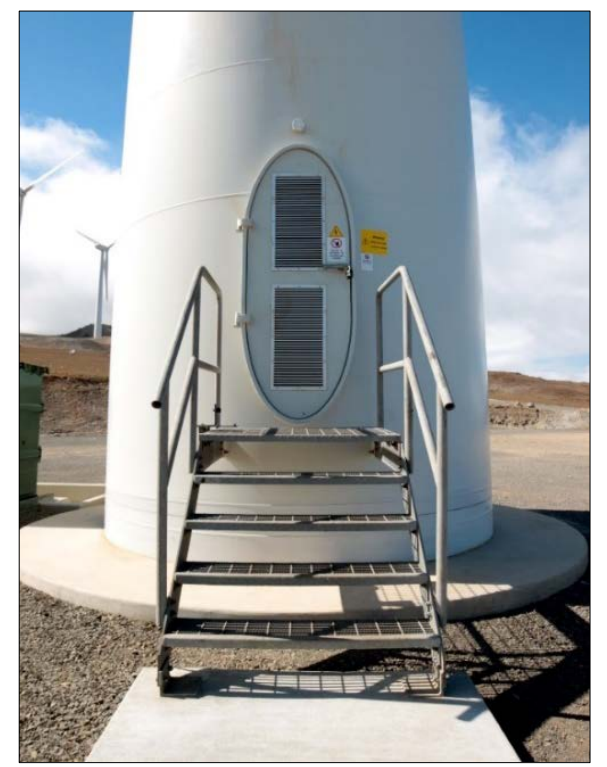

Figure 19. Locking door and warning signs on a wind turbine entrance. Photo by Travis

\footnotetext{
35 The authors calculated this value using a wind turbine with a 90-m hub height and 121-m rotor diameter based on the "2020 Wind Energy Technology Data Update" (Wiser et al. 2020).
} 


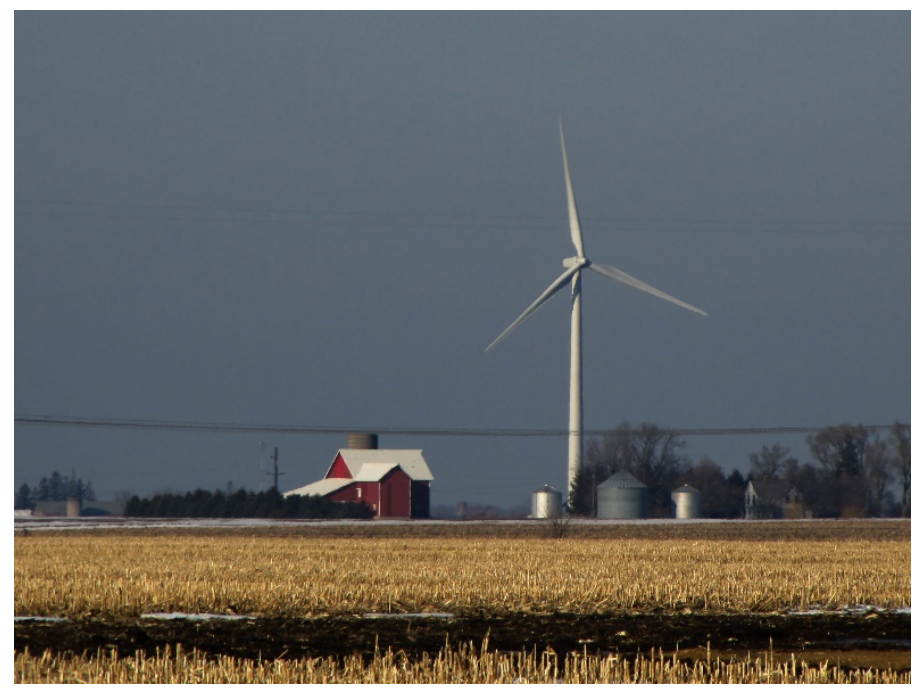

Figure 20. A wind turbine shown in the distance from an Illinois farm. Photo by Tracy

\section{Safety and Decommissioning}

Some communities have found it important to ensure the future safe use of a site once a project's operational life is over. The primary example in ordinances reviewed for this guide was community-defined removal depths to ensure that remaining foundation or collection system wiring will not interfere with farming, root zones of typically grown crops, or future road construction and utility installation.

\section{Resources}

For more information on safety, see:

- FAA. Advisory Circular No 70/7460-IL. "Subject: Obstruction Marking and Lighting."

- WINDExchange. "Wind Energy Projects and Safety."

\subsection{Shadow Flicker}

This section explores shadow flicker, the effect of moving wind turbine blades as they block sunlight and cast a moving shadow (see Figure 21).

\section{Considerations}

Whether a residence will experience shadow flicker depends on the distance between the dwelling and the wind turbine as well as the time of day and season. The flicker effect only occurs on sunny days when the sun is at a certain angle behind a turbine. The general size of the wind turbine (height and rotor diameter) and the surrounding landscape also play an important role in determining the areas that receive flicker impact (NYSERDA 2017). During the early morning or evening on a clear day when the sun is low on the horizon, the shadow from a wind turbine will shift spatially, creating a butterfly-like pattern (New England Wind Energy Education Project [NEWEEP] 2011). 


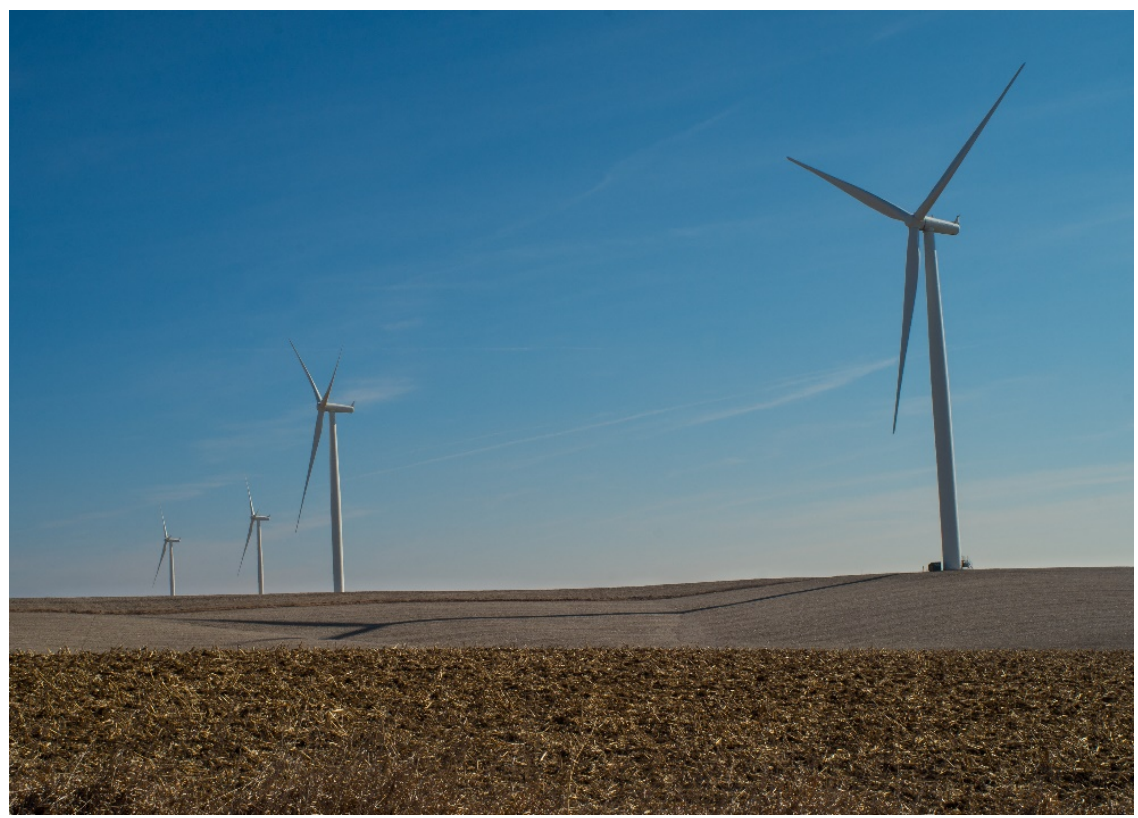

Figure 21. The shadow of a wind turbine appears on the land beneath the installation. Photo by Pollys Belivin

The extent of shadow flicker also depends on factors such as wind speed, wind direction, and cloud cover. For example, even if the angle of the sun is conducive to shadow flicker, the effect will be experienced only if winds are high enough for the wind turbine to operate. Cloud cover also plays an integral role because clouds can reduce shadow intensity and generally increase the impact of this effect.

Although shadow flicker from a wind energy project will not be experienced by every dwelling in a community, some residences could be impacted for a few hours every year. Depending on their use, public buildings, roads, or other areas of interest might be affected by shadow flicker. As with residences, the impact on local infrastructure and areas of interest depends on the wind turbine location, time of day, and season.

Shadow flicker can be perceived as an annoyance; however, it does not occur at a rate high enough to induce seizures. Epileptic seizures brought on by light flashes occur from 5-30 hertz (Hz) (Epilepsy Foundation 2019), whereas wind turbines create flicker from 0.6-1 Hz. Other health concerns related to shadow flicker from wind turbines, such as headaches and dizziness, are not supported by peer-reviewed research (NEWEEP 2011).

\section{Best Practices and Mitigation Strategies}

From the community perspective, shadow flicker can be addressed using limits that define a maximum number of hours per year at specific locations. Most developers strive to limit shadow flicker to no more than 30 hours per year on any nonparticipating residence ${ }^{36}$ based on predictions of weather and operations. Some local and state governments have regulations that require the same limits.

\footnotetext{
${ }^{36}$ A nonparticipating residence is a residence whose owner is not receiving direct compensation for agreeing to have a wind turbine or project infrastructure on their land.
} 
To determine the duration exposure, or number of hours of flicker per year, that could affect individual locations (e.g., residence, local infrastructure, and other areas of interest), project developers and owners use shadow flicker models. Computer modeling has made it possible to predict shadow flicker impacts-including location and duration-before project construction. Modeling results can show times of day and portions of the year when shadow flicker is possible (NEWEEP 2011). Developers use modeling outputs to inform siting decisions and identify the need for mitigation strategies. These models are often produced with two data sets: a worst case and a realistic case. The worst case will include assumptions in which the wind is always blowing, shadows will be cast in every direction from a wind turbine, and there is no cloud cover during daylight hours. The realistic case will calculate a reasonable number of hours of shadow flicker to be expected using adjustments based on wind turbine operation time and direction and on weather predictions (e.g., sunshine). The realistic case will often still be conservative-for example, by not trying to predict reductions in shadow flicker from trees and structures. Models assume houses are comprised entirely of windows, meaning any flicker on the house would be visible to occupants.

Once project developers and owners have modeled shadow flicker, they can use the findings to inform project layout and minimize its occurrence. If the duration exposure is expected to exceed established limits, project developers and owners might negotiate easements with specific landowners for exemptions. In case limits are exceeded and no easement is in place, wind farm operators might be required to curtail operations, shut down noncompliant wind turbines, or engage in localized mitigation efforts (e.g., planting trees to diffuse flicker or providing new blinds or curtains for the affected houses).

\section{Shadow Flicker and Height Limits}

The height ${ }^{37}$ and rotor diameter of a wind turbine are factors in determining the extent of shadow flicker impacts; however, local height limits that specify the maximum height for a wind turbine are not an effective way to lessen shadow flicker and may have unintended consequences such as reduced strength of wind resource and reduced interest from developers that can affect project potential. The potential impact can be modeled, and the information can be used to design a project layout that reduces shadow flicker.

\section{Shadow Flicker and Setback Limits}

Setbacks can help determine the extent of shadow flicker impacts by defining the distance between a wind turbine and many areas of interest that have shadow flicker concerns. Yet, with new modeling capabilities, setback limits are not necessary. In fact, attempts to lessen shadow flicker with setbacks may have unintended consequences such as an exclusion of small landowners and a decreased number of total wind turbines that can affect project potential.

\section{Resources}

For more information on shadow flicker, see:

- Center for Rural Affairs. Fact Sheet: Wind Energy and Shadow Flicker.

\footnotetext{
${ }^{37}$ Wind turbine heights can be defined in multiple ways: the distance from the base of the tower to the hub or nacelle, the base of the tower to the tip of a blade when extended vertically, or the base of the tower to the top of the tower.
} 
- New England Wind Energy Education Project. "Understanding the Current Science, Regulation, and Mitigation of Shadow Flicker: A NEWEEP Webinar."

- U.K. Department of Energy and Climate Change. "Update of U.K. Shadow Flicker evidence base."

\subsection{Signal Interference}

This section discusses the disruption of communications and radar equipment ${ }^{38}$ because of signal interception by a wind turbine.

\section{Considerations}

Potential signal interference can be predicted, modeled, and mitigated. The extent of any signal interference depends on wind turbine height, rotor swept area, rotational speed, and local landscape.

Transmission from radio or television broadcast frequencies can be influenced by obstructions between the transmitter and the receiver, leaving a portion of households susceptible to potential interference (U.S. Department of Energy [DOE] 2015). This means that some residents who use outdoor antennas, "rabbit ear" antennas, and/or older high-definition television receivers might experience reception issues (Evans 2018). Wind energy project developers typically perform television/radio studies prior to design to reduce the potential for these types of impacts. Mitigation options - such as better antennas or switching to satellite or cable service (typically at the developer's or project owner's expense, per their discretion) — can also help. Further, participating landowners might include language addressing this issue within their land lease agreements.

Interference with microwave-based line-of-sight communications might also occur. In many areas, project developers are required by state and local permitting agencies, as well as many financing companies, to perform a communications impact analysis or its equivalent to demonstrate that pathways between communicating towers are unobstructed prior to approval of project construction or operational permits. If a potential obstruction is identified, mitigation options can be applied at the wind power plant or on the microwave towers (DOE 2015).

Wind energy projects being planned and sited in the line of sight of military or weather radar systems may impact the operation of those radars. Understanding project or development impacts that may cause clutter or interference for radar systems involved in air traffic control, weather forecasting, homeland security, and national defense missions is critical for proper mitigation.

Siting alone may not eliminate impacts or reduce them to an acceptable level. In these cases, other mitigation techniques, including the deployment of new radar-related software upgrades and/or hardware, can also reduce potential wind energy impacts on radar operations. Radar impacts can include inhibiting detection, generating false images, interfering with tracking, and hindering critical weather forecasts (DOE 2015). Early coordination with the FAA, National Oceanic and Atmospheric Administration, U.S. Department of Homeland Security, and DOD Military Aviation and Installation Assurance Siting Clearinghouse during the siting process can help prevent an interference issue before a facility is built. To address military interests, the FAA's mandatory

\footnotetext{
${ }^{38}$ Communications and radar equipment can include microwave; radio; television; personal, official, or emergency communications systems; other wireless applications and/or radar equipment for air traffic; weather; or military.
} 
obstruction evaluation review process activates the formal DOD Mission Compatibility Evaluation Process assessment and U.S. Department of Homeland Security assessments (DOE undated [a]). In most cases, siting and other mitigation efforts have resolved conflicts and allowed wind energy projects to coexist effectively with radar missions. However, in some proposed locations, wind turbines will cause disruptive radar interference that cannot be effectively mitigated. At such sites, wind energy development would likely not proceed.

\section{Resources}

For more information on signal interference, see:

- ACP. Radar and Airspace Fact Sheet.

- DOD. "Military Aviation and Installation Assurance Siting Clearinghouse."

- DOD. "DoD Preliminary Screening Tool."

- WINDExchange. "Wind Turbine Radar Interference."

\subsection{Sound}

This section explores the audible or inaudible pressure fluctuations experienced by humans when components within the wind turbine (mechanical) operate or when the turbine blades interact with the air as they rotate (aerodynamic). These fluctuations can be categorized into four types of sound: tonal, impulsive, broadband, and infrasound.

\section{Considerations}

Although scientific evidence does not support a causal link between wind turbine sound and negative human health impacts, some residents have expressed annoyance from wind turbine sound. Research shows that these feelings of annoyance are more closely correlated to attitudes toward the wind turbines than the sound audibility itself (Hoen et al. 2019). To better understand concerns related to sound impacts, community decision makers should visit an operating wind farm. This in-person experience can help inform communities about the spectrum of wind turbine sound and how it is influenced by a variety of factors, including ambient (existing) sound levels, ${ }^{39}$ variable atmospheric conditions, ${ }^{40}$ the wind turbine model, distance between the project and the listener (Figure 22), and individual perception.

\footnotetext{
${ }^{39}$ Automobile traffic, airplane flights, birdcalls, and insects are other common ambient sounds

${ }^{40}$ Atmospheric conditions include temperature, humidity, airflow patterns, turbulence, and general weather conditions.
} 


\section{Have you ever heard sound from the wind power project?}

\begin{tabular}{|c|c|c|c|}
\hline \multicolumn{3}{|c|}{$84 \%$} & $16 \%$ \\
\hline \multicolumn{4}{|c|}{ Within 1 mile $(n=1,112)$} \\
\hline & $44 \%$ & \multicolumn{2}{|l|}{$56 \%$} \\
\hline \multicolumn{4}{|c|}{ Within $1 / 2$ mile $(n=619)$} \\
\hline $19 \%$ & \multicolumn{3}{|c|}{$81 \%$} \\
\hline No & \multicolumn{3}{|c|}{ Yes } \\
\hline
\end{tabular}

Figure 22. The distribution of respondents who reported hearing wind turbines by distance. Source: Hoen et al. (2019)

The ambient sound level in each area (Figure 23) plays a role in how a wind energy project's sound is perceived, as does the volume of the wind blowing at ear level. Ambient sound levels depend on a variety of site-specific factors, including the surrounding landscape (both humanmade and natural terrain features), surrounding foliage and season, distance to natural sound producers (e.g., rivers, waterfalls), proximity to traffic developments (e.g., highways and roads), and the general amount and type of local activity. In areas where wind energy projects are planned, the noise from the wind itself and its interaction with local vegetation is often the most significant source of ambient sound (e.g., wind rustling dry corn stalks). Automobile traffic, airplane flights, birdcalls, and insects are other common ambient sounds.

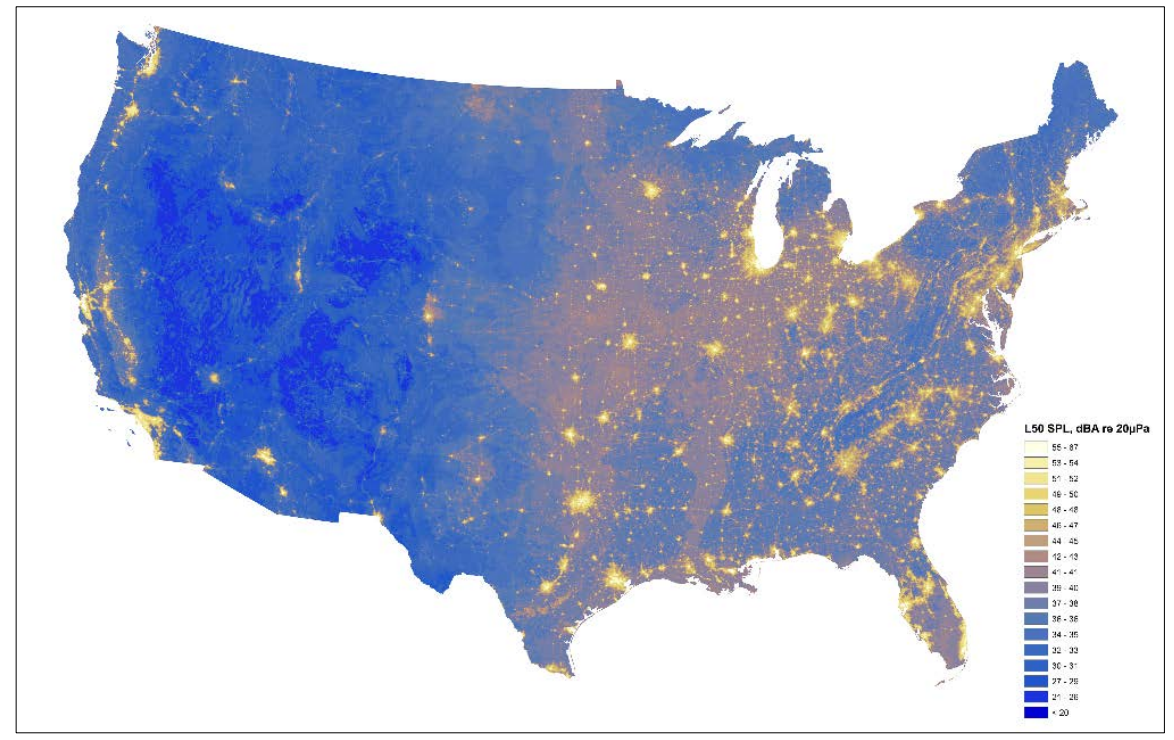

Figure 23. A National Park Service map showing existing ambient sound levels across the country. Source: U.S. Department of the Interior (2017)

Though sound naturally dissipates over distance, community sound experience can change depending on whether an area has human-made (e.g., buildings) or natural terrain features (e.g., hills, forests) that can influence the distance or spread of sounds created from wind turbines. Areas that are mostly flat and free of obstructions have fewer features that can interrupt or otherwise influence wind turbine sound. 
Sound spread is also impacted by local atmospheric conditions, whereas absorption is influenced by the amount of space between an individual and a wind turbine. Though setbacks can be created to ensure sufficient distance between a project and specific landscape features, such as a house or barn, a fixed setback distance will not necessarily limit sound equally for all receptors around a wind facility because of variations in how sound travels. On very windy days, the sound from the wind could exceed that of the wind turbines.

The sound output of a wind energy project depends primarily on the make, model, and operation of the selected wind turbine because sound levels vary across the spectrum of available technology. Other key factors include the quantity and location of nearby wind turbines.

Like other sources of sound, wind turbines can emit a broad array of mechanical and aerodynamic sounds. One example is tonal sound, which is sound levels of constant pitch, such as those created by the rotation of shafts, generators, and gears; or airflow over holes or slits (DOE undated [b]). Because tonal sounds can be perceived as annoying, wind turbine manufacturers have worked to minimize them. In many cases, the presence of tonal sounds could indicate a maintenance issue.

Aerodynamic sounds can vary in volume as wind turbine blades rotate, creating a continuously changing loudness level (amplitude modulation). When airflow interacts with wind turbine blades, it can make periodic swishing sounds. When combined with changing loudness, these periodic swishing sounds can be perceived as impulsive ${ }^{41}$ (NYSERDA 2013). The extent to which changes in loudness might be experienced also varies depending on atmospheric conditions and the listener's location.

The relatively even distribution of sound waves with different frequencies (e.g., low through high, $20-20,000 \mathrm{~Hz}$ ) is referred to as broadband sound. It has no distinct pitch and could be described as a humming sound (DOE undated $[\mathrm{b}]$ ). However, some wind turbine sound might be perceived as broadband, similar to passing traffic.

The lowest level of sound created during wind turbine operation is infrasound - a very lowfrequency sound (less than $20 \mathrm{~Hz}$ ) that is always present in the environment and inaudible to people (NYSERDA 2013). Infrasound is generated by everything from traffic and ocean waves to the human heartbeat and is not dangerous to humans. The infrasound generated by wind turbines is similar to the inaudible levels produced by ocean waves. Low-frequency sound (20-100 Hz) and infrasound travel farther than higher, more audible frequencies because of limited atmospheric absorption and the fact that human-made and natural structures only partially modify lowfrequency sound. A long-term study by the VTT Technical Research Centre of Finland, the Finnish Institute for Health and Welfare, the Finnish Occupational Safety and Health Administration, and the University of Helsinki revealed that both wind-turbine-produced infrasound levels and the relative loudness perceived by the human ear were similar to the levels occurring typically in an urban environment. The study found no evidence of health effects from wind turbine infrasound (VTT 2020).

\footnotetext{
${ }^{41}$ Impulsive sound is the instantaneous change in sound pressure over a short period of time (e.g., a door slamming or a nail gun).
} 


\section{Best Practices and Mitigation Studies}

In some areas, wind energy sound is regulated at the state level; however, many communities are tasked with establishing related procedures and limitations through their local ordinances. Approaches often include limits for sound levels and complaint procedures.

\section{Conducting Sound Studies}

Some counties find that understanding preproject ambient sound levels can provide context for expected changes in the local auditory experience and magnitudes of sound levels resulting from a wind energy project (National Association of Regulatory Utility Commissioners 2011). To achieve this understanding, local ordinances can require project developers/owners to conduct ambient sound studies in a project area prior to project approval and construction. Data from these studies can be compared to acoustic modeling to determine the expected change in sound as a result of turbine type, local atmospheric conditions, and landscape, as well as distance to areas of concern. Communities can also require that developers do a postconstruction sound assessment to verify the project is operating within the approved sound range.

Understanding sound impacts from wind turbines is complex, and many aspects should include guidance from technical experts. Some communities have defined sound verification methods to accurately measure and confirm the sound output from a wind energy project. Such methods can involve defining the type of sound being measured, the specific measuring device, allowable testing conditions, and specific locations for testing. Organizations such as the Institute of Electrical and Electronics Engineers, International Electrotechnical Commission, and the American National Standards Institute have developed standards to measure, model, and set sound limits. These standards are often included in local ordinances.

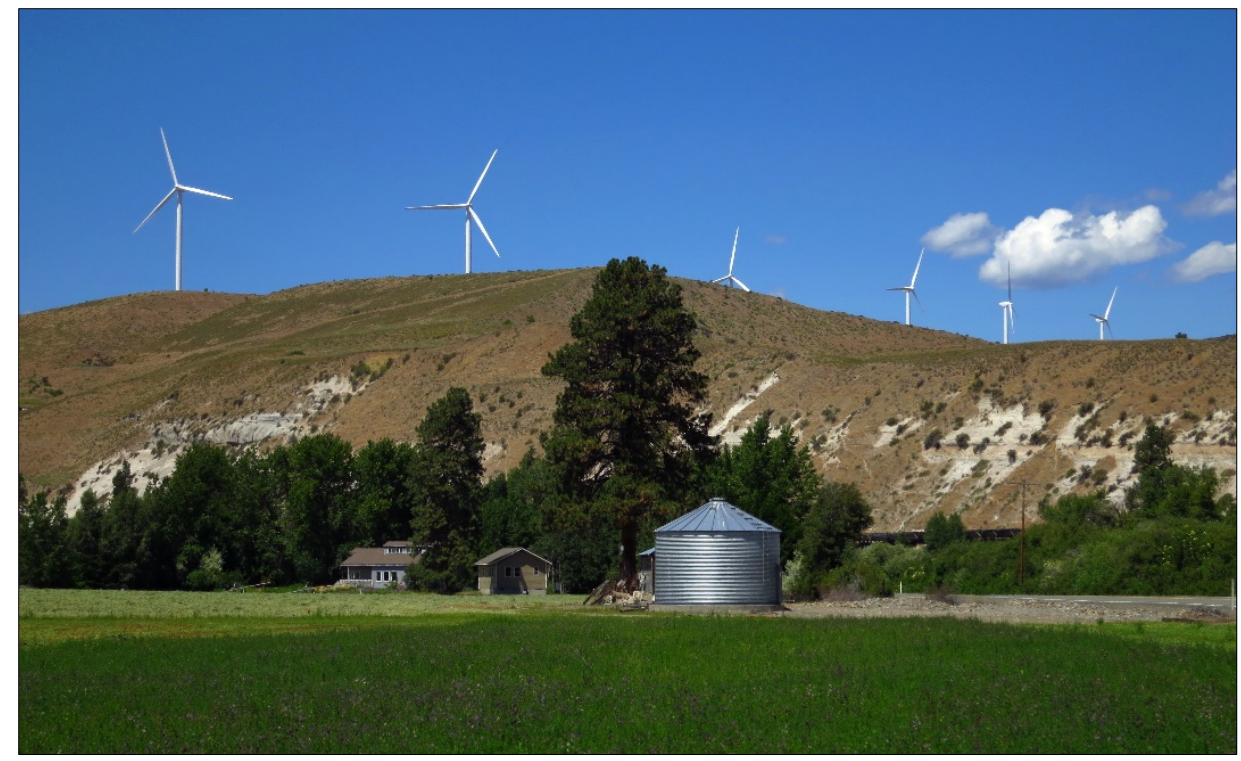

Figure 24. Wind turbines approximately 1 mile away from a farm in Kittitas County, Washington. Photo by Steve Cyr 


\section{Mitigation Strategies}

Some communities approach sound limits by establishing a single upper threshold for acceptable maximum sound levels at noise-sensitive receptors, such as houses. Communities can also create separate standards for daytime and nighttime operations. Nighttime levels typically feature a lower upper threshold than daytime to limit noise when most of the population is sleeping. Another variation is limited exceptions: temporarily allowing wind turbines to operate at sound levels that exceed maximum limitations during isolated events, usually related to weather such as a high wind event.

Some communities require project developers and owners to establish complaint procedures to provide community members with a way to voice sound-related grievances. These procedures can also define the methods and timelines for developers and owners when addressing those concerns (Manwell et al. 2010).

\section{Sound and Setback Limits}

The distance between a wind turbine and identified areas of interest (see Figure 24) is a factor in determining the extent of sound impacts - but not the only factor, as mentioned earlier. Therefore, setbacks alone will not be an effective way to mitigate sound impacts.

\section{Resources}

For more information on sound, see:

- Journal of the Acoustical Society of America 146, no. 2. "Wind Turbine Audibility and Noise Annoyance in a National U.S. Survey: Individual Perception and Influencing Factors."

- Massachusetts Clean Energy Center, Massachusetts Department of Environmental Protection. "Massachusetts Study on Wind Turbine Acoustics."

- Prepared for the Massachusetts Department of Environmental Protection, Massachusetts Department of Public Health. "Wind Turbine Health Impact Study: Report of Independent Expert Panel."

- NYSERDA. "New York State Wind Energy Guidebook." (Noise, pages 10-12, and Sound Emissions, pages 80-85).

- NYSERDA. Wind - R\&D Technical Reports. "Wind Turbine-Related Noise: Current Knowledge and Research Needs."

- VTT Technical Research Centre of Finland. "VTT studied the health effects of infrasound in wind turbine noise in a multidisciplinary cooperation study."

- World Health Organization. "Environmental Noise Guidelines for the European Region." (Section 3.4). 


\subsection{Viewshed}

This section discusses the effect of wind turbines on a community's existing scenery and visual experience, otherwise known as viewshed.

\section{Considerations}

Landscape changes that impact views are some of the most frequently cited reasons that people oppose proposed wind energy projects or have negative attitudes toward operating wind facilities. To better address this, communities must understand the ways in which a wind energy project can change a local landscape. Although some potential impacts of wind energy development can be measured quantitatively, visual impacts are more qualitative and based on an individual's perceptions of and interaction with their surroundings.

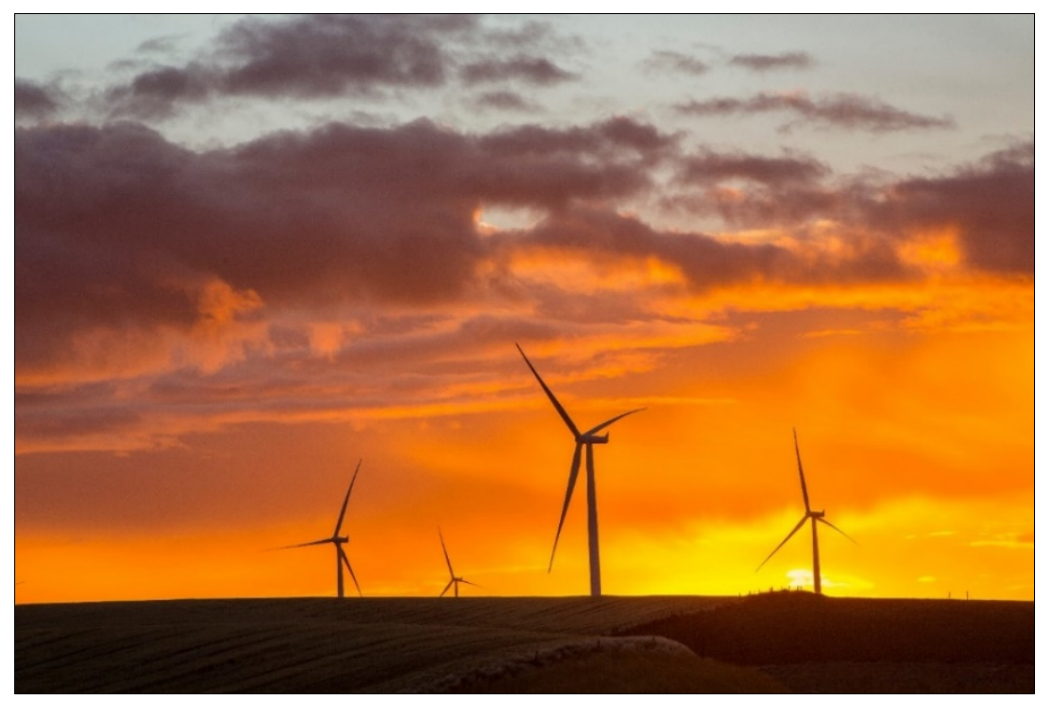

Figure 25. Wind turbines at the Tucannon River Wind Farm near Dayton, Washington. Photo from Portland General Electric

Wind energy facilities will have different visual effects during the day than at night. Daytime attributes relate largely to appearance (e.g., color), whereas nighttime factors relate mostly to lighting. Factors influencing daytime viewshed impacts include wind turbine height, rotor diameter, total number of turbines, density of turbines, overall distance between the turbine(s) and viewer, and any obstructions that exist near a viewer's property (e.g., trees, barns, bushes). In 2019, the average wind turbine had a total height (base to tip) of more than $494 \mathrm{ft}$, with a rotor diameter of slightly more than $397 \mathrm{ft}$ (Wiser et al. 2020). Future wind turbine models are anticipated to be even taller, often making a new wind turbine the tallest object in a rural skyline. Unlike other passive objects in a viewshed, wind turbines are active objects with rotating blades. This movement can produce temporary shadow flicker (Section 2.9) at certain distances and times of day. In addition, some communities might want project uniformity and limits on advertisements or logos on wind turbines.

While some appearance aspects of individual wind turbines may be governed by local ordinances or agreements with the developer or project owner, most are regulated by the FAA. Nighttime visual impacts come primarily from FAA-mandated lighting requirements but can be better mitigated with an ADLS (Figure 26). FAA regulations require synchronized red lights at the top of 
the wind turbine (one for turbines $499 \mathrm{ft}$ or less and two for turbines $499 \mathrm{ft}$ or more), with no unlit turbine separations or gaps of more than a half mile. Wind turbines taller than $699 \mathrm{ft}$ are required to have three midtower lights as well as two top lights (FAA 2015). Nighttime visual impacts can also come from lighting used for general site safety or security.

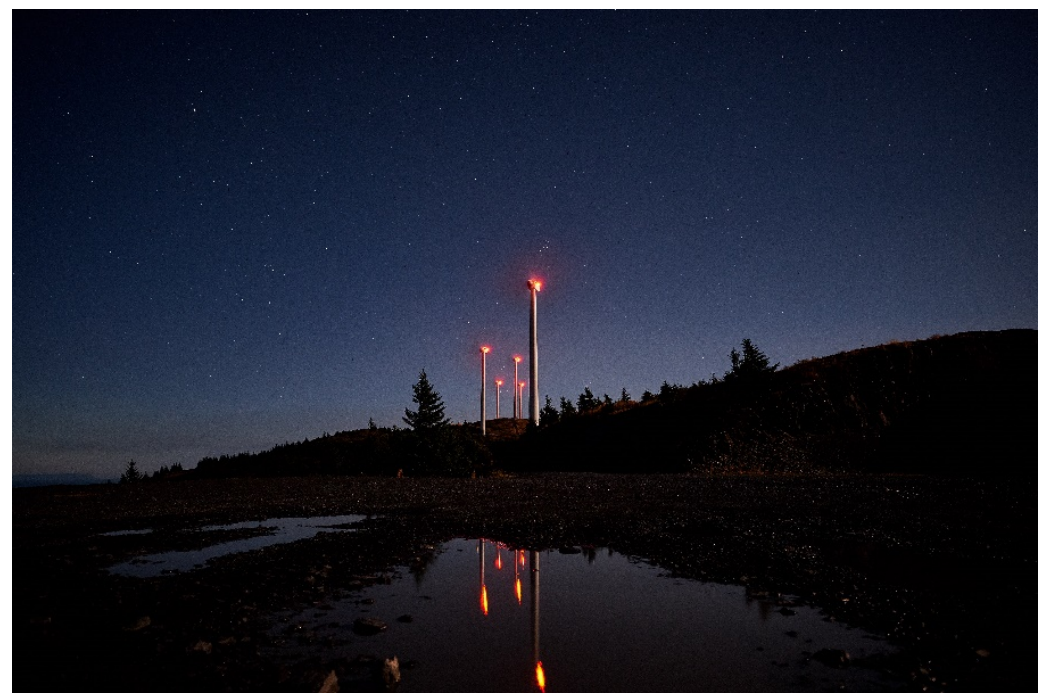

Figure 26. Wind turbines with nighttime lights in Kodiak, Alaska. Photo by naql

\section{Best Practices and Mitigation Strategies}

\section{Appearance}

Existing community ordinances about the visual appearance of wind turbines discuss attributes such as paint color and style. For example, an ordinance might read, "paint should be a nonreflective, nonobtrusive color, such as white, gray, earth tone, or beige, which blends with the environment based on the character of the area." Some of this language often applies to other project infrastructure as well (e.g., substation, O\&M building). In contrast, FAA recommendations typically include white paint for all wind turbines within a project. A project developer or owner may also be required to blend project infrastructure into the natural surroundings by planting trees and shrubs as screening or painting project infrastructure in neutral tones that blend in with the colors of the landscape.

\section{Advertising and Logos}

If a community wants to limit the use of wind turbines for commercial advertising such as logos, they can include such language in their ordinances.

\section{Nighttime Lighting and Visual Impacts}

Nighttime lighting requirements are important to ensuring the safe operation of commercial, private, military, and rescue aircraft. Any local regulations need to be consistent with FAA requirements. For any project using wind turbines with a total height (base to tip) of more than 200 $\mathrm{ft}$, the FAA will make decisions on required obstruction lights based on the current version of FAA Advisory Circular 70/7460-1, Obstruction Marking and Lighting. 


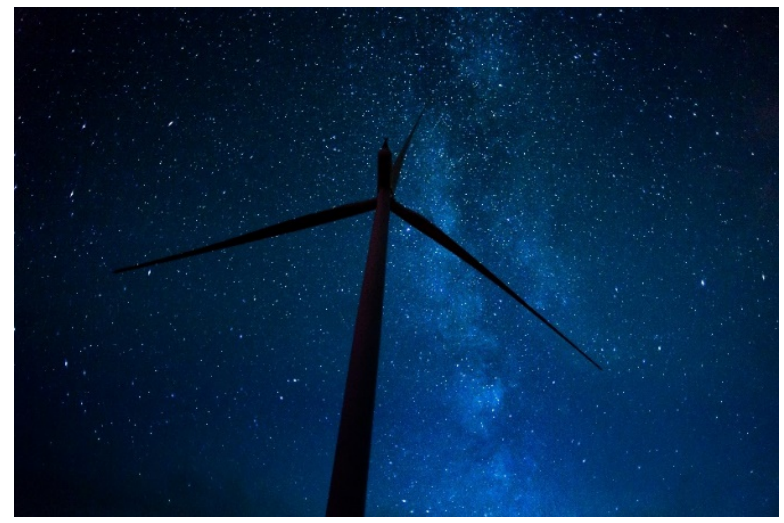

Figure 27. Wind turbine without nighttime lighting at the Tucannon River Wind Farm near Dayton, Washington. Photo from Portland General Electric

In 2016, FAA approved the ADLS, which limits nighttime lighting of wind turbines when aircraft are not present (see Figure 27) (FAA 2016). Use of an ADLS must be reviewed and approved by the FAA and included in the initial FAA notice of filing. Additionally, the lighting system must be manufactured by an FAA-approved vendor. Other mitigation technologies or plans might apply if the use of an ADLS is not approved by the FAA. In 2017, North Dakota enacted a law that required wind energy projects to use systems that limit nighttime lighting statewide (Bismarck Tribune 2017). Similar language has been included in county ordinances in other states.

Other project facilities, such as the O\&M building and substation, might use lighting for security. Ordinances may require such lighting to be directed downward or activated by motion. Because facility lighting is most likely to impact nearby residences, it is reasonable to require developers to address and lessen complaints relating to a project's facility lighting.

During construction and maintenance, developers or owners might need to perform certain activities at night. Communities can establish stipulations for such activities, including how often or how late they can operate.

Viewshed and Height Standards, Setback Limits

Height and setbacks are important in overall visual impacts because variations between the two (and rotor diameter) partially determine how a project or individual wind turbine are visually perceived from a given area.

To understand the visual impact of these variables and help address viewshed concerns, including on areas of cultural and/or historical significance, some communities require project developers or owners to provide a sightline analysis with photo simulations of the proposed wind energy project. Further, communities can use findings from this analysis to negotiate setbacks to specifically address areas of interest.

Attempts to mitigate visual impacts through height restrictions might have unintended consequences such as reduced strength of wind resource and reduced interest from developers that can affect project potential.. 


\section{Viewshed and Shadow Flicker}

Shadow flicker is one element of overall viewshed considerations. Not every dwelling in a community will experience shadow flicker from a wind energy project; however, some residences could be impacted for a few hours every year. For more information, refer to Section 2.9.

\section{Resources}

For more information on viewshed, see:

- Clean Energy States Alliance. "A Visual Impacts Assessment Process for Wind Energy Projects."

- NYSERDA. "New York State Wind Energy Guidebook." 


\section{References}

American Clean Power. 2020. Wind Project Decommissioning: Industry Management Practices. https://cleanpower.org/resources/wind-project-decommissioning-industry-managementpractices/.

American Wind Energy Association. 2020. Wind Powers America Amended Annual Report 2019. Washington, D.C. https://www.powermag.com/wpcontent/uploads/2020/04/awea_wpa_executivesummary2019.pdf.

American Wind Wildlife Institute. Undated. "Wind Energy Siting: Resources for Preliminary Site Assessment.” https://awwi.org/resources/wind-siting-resources/.

American Wind Wildlife Institute. 2018. Bats and Wind Energy: Impacts, Mitigation, and Tradeoffs. https://awwi.org/wp-content/uploads/2018/11/AWWI-Bats-and-Wind-Energy-WhitePaper-FINAL.pdf.

André, Don, Jennifer Grove, Leslie Grossman Moynihan, Sarah Peterson, Jessica Raker. 2006. Community Wind: An Oregon Guidebook. Energy Trust of Oregon. https://www.energytrust.org/wp-content/uploads/2016/10/cw pg_commwindguidebook.pdf.

Arnett, E. B., G. D. Johnson, W. P. Erickson, and C. D. Hein. 2013. "A Synthesis of Operational Mitigation Studies to Reduce Bat Fatalities at Wind Energy Facilities in North America." Bat Conservation International. Austin, TX.

https:/www.energy.gov/sites/prod/files/2015/03/f20/Operational-Mitigation-Synthesis-FINALREPORT-UPDATED.pdf.

Bismarck Tribune. 2017. "Wind turbine bill passes in Legislature." https://bismarcktribune.com/wind-turbine-bill-passes-in-legislature/article_41c1080e-aa7f-5250abb0-fd282067e022.html\#tracking-source=article-related-bottom.

Canadian Wind Energy Association. Undated. "Wind Energy and Land Use - an Advantage for Landowners and Communities." https://canwea.ca/communities/land-use/.

Chernyakhovskiy, Ilya, Tian, Joyce McLaren, MacKay Miller, and Nina Geller. 2016. U.S. Laws and Regulations for Renewable Energy Grid Interconnections. Golden, CO: National Renewable Energy Laboratory (NREL). NREL/TP-6A20-66724.

https://www.nrel.gov/docs/fy16osti/66724.pdf.

Cornell Law School. Undated. "Regulation."

https://www.law.cornell.edu/wex/regulation\#: :text=Definition,rules $\% 2 \mathrm{C} \% 20$ or $\% 20 \% 22$ regulati ons $\% 22$. 
County of San Diego. 2018. Notice of Preparation Documentation. (Torrey Wind). https://www.sandiegocounty.gov/content/dam/sdc/pds/ceqa/TorreyWind/TWNOP/Torrey\%20Wi nd $\% 20$ NOP $\% 20$ and $\% 20$ Initial $\% 20$ Study $\% 20$ Final $\% 208-9-18$.pdf.

Denholm, Paul, Maureen Hand, Maddalena Jackson, Sean Ong. 2009. Land-Use Requirements of Modern Wind Power Plants in the United States. Golden, CO: National Renewable Energy Laboratory (NREL). NREL/TP-6A2-4583. https://www.nrel.gov/docs/fy09osti/45834.pdf.

Diffendorfer, Jay, and Roger Compton. 2014. "Land Cover and Topography Affect the Land Transformation Caused by Wind Facilities.” PLoS ONE 9(2): e88914.

https://journals.plos.org/plosone/article?id=10.1371/journal.pone.0088914\#pone-0088914-g001.

Diffendorfer, Jay, Monica Dorning, Jolene Keen, Louisa Kramer, and Robert Taylor. 2019. "Geographic context affects the landscape change and fragmentation caused by wind energy facilities.” PeerJ Vol. 7 e7129. https://www.ncbi.nlm.nih.gov/pmc/articles/PMC6640624/.

Donohoo-Vallett, Pearl, Michael Milligan, and Bethany Frew. 2015. "Capricious Cables: Understanding the Limitations and Context of Transmission Expansion Planning Models." The Electricity Journal. Volume 28, Issue 9. Pg. 85-99.

https://www.sciencedirect.com/science/article/pii/S1040619015002079.

Echavarria, E., G. J. W. van Bussel, T. Tomiyama. 2012. "Finding functional redundancies in offshore wind turbine design." Wind Energy. Volume 15, Issue 4. Pg. 609-626.

https://onlinelibrary.wiley.com/doi/full/10.1002/we.490.

Electronic Code of Federal Regulations (e-CFR). 2021. Title 40: Protection of Environment, Part 1508-Definitions. https://www.ecfr.gov/cgi-bin/text$\underline{\mathrm{idx}}$ ?SID=b8e357969cec1b9f0e5b6a7ae1f574f4\&mc=true\&node=pt40.37.1508\&rgn=div5\#se40. 37.1508 11.

Epilepsy Foundation. 2019. "Photosensitivity and Seizures." https://www.epilepsy.com/learn/triggers-seizures/photosensitivity-and-seizures.

Erickson, W., Johnson, G., Young, D., Strickland, D., Good, R., Bourassa, M., Bay, K., Sernka, K. 2002. Synthesis and Comparison of Baseline Avian and Bat Use, Raptor Nesting and Mortality Information from Proposed and Existing Wind Developments. Cheyenne, WY: West, Inc.

http://www.altamontsrcarchive.org/alt_doc/west_synthesis_and_comparison_etc_study_dec_200 2 for bpa.pdf.

Evans, Benjamin. 2018. Appendix H; Telecommunications Studies; Community Wind North Repower Project. Appendix H. Evans Engineering Solutions. https://mn.gov/eera/web/projectfile/11039/. 
Federal Aviation Administration (FAA). 2015. Advisory Circular: Obstruction Marking and Lighting. https://www.faa.gov/documentlibrary/media/advisory_circular/ac_70_7460-11_.pdf.

FAA. 2016. Advisory Circular: Obstruction Marking and Lighting.

https://www.faa.gov/documentLibrary/media/Advisory_Circular/AC_70 7460-

1L_Change_1_Obstruction_Marking_and_Lighting_10062016.pdf.

FAA. 2017. Advisory Circular: Certification Process for Agricultural Aircraft Operators. https://www.faa.gov/documentLibrary/media/Advisory_Circular/AC 137-1B.pdf.

Federal Energy Regulatory Commission. 2021. "Power Sales and Markets: RTOs and ISOs." https://www.ferc.gov/industries-data/electric/power-sales-and-markets/rtos-and-isos.

Flight for Life. Undated. "Position Statement Regarding Wind Turbines and Safe Landing Zones."

http://fflintranet.northwoodsoft.com/FlightForLifePublic/Group1/FFL/Flyers/WAMCPositionSta tementRegardingWindTurbinesandSafeLandingZonesrevffl1.pdf.

Hanna, Luke, Andrea Copping, Simon Geerlofs, Luke Feinberg, Jocelyn Brown-Saracino, Patrick Gilman, Finlay Bennet, Roel May, Johann Köppel, Lea Bulling, Victoria Gartman. 2016. Assessing Environmental Effects (WREN): Adaptive Management White Paper. IEA Wind Task 34. https://tethys.pnnl.gov/sites/default/files/publications/WREN-AM-White-Paper-2016 0.pdf.

Hoen, Ben, Ryan Wiser, Peter Cappers, Mark Thayer, and Gautam Sethi. 2009. The Impact of Wind Power Projects on Residential Property Values in the United States: A Multi-Site Hedonic Analysis. Berkeley, CA: Lawrence Berkeley National Laboratory. LBNL-2829E https://etapublications.1bl.gov/sites/default/files/report-1bnl-2829e.pdf.

Hoen, Ben, Ryan Wiser, Peter Cappers, Mark Thayer, and Gautam Sethi. 2011. Wind Energy Facilities and Residential Properties: The Effect of Proximity and View on Sales Prices. Berkeley, CA: Lawrence Berkeley National Laboratory. LBNL-4822E. https://escholarship.org/uc/item/2k02b6x8\#main.

Hoen, Ben, Jason P. Brown, Thomas Jackson, Ryan H. Wiser, Mark A. Thayer, Peter Cappers. 2013. A Spatial Hedonic Analysis of the Effects of Wind Energy Facilities on Surrounding Property Values in the United States. Berkeley, CA: Lawrence Berkeley National Laboratory. LBNL-6362E. https://emp.lbl.gov/publications/spatial-hedonic-analysis-effects-wind.

Hoen, Ben, Joseph Rand, Ryan Wiser, Jeremy Firestone, Debi Elliott, Gundula Hübner, Johannes Pohl, Ryan Haac, Ken Kaliski, Matt Landis, Eric Lantz. 2019. National Survey of Attitudes of Wind Power Project Neighbors: Summary of Results. Lawrence Berkeley National Laboratory.

https://emp.lbl.gov/sites/default/files/wind_neighbors_survey_summary_nov2019v5 final.pdf. 
Institute for Local Government. 2010. Understanding the Basics of Land Use and Planning: Glossary of Land Use and Planning Terms. https://www.ca-ilg.org/sites/main/files/fileattachments/2010 - landuseglossary.pdf.

Manwell, James, Jon McGowan, and Anthony Rogers. 2010. Wind Energy Explained: Theory, Design and Application, Second Edition. Hoboken: Wiley. https://onlinelibrary.wiley.com/doi/book/10.1002/9781119994367.

Milligan, Michael, Brendan Kirby, Tom Acker, Mark Ahlstrom, Bethany Frew, Michael Goggin, Warren Lasher, Melinda Marquis, Dale Osborn. 2015. Review and Status of Wind Integration and Transmission in the United States: Key Issues and Lessons Learned. Golden, CO: National Renewable Energy Laboratory (NREL). NREL/TP-5D00-61911.

https://www.nrel.gov/docs/fy15osti/61911.pdf.

National Association of Regulatory Utility Commissioners. 2011. Assessing Sound Emissions from Proposed Wind Farms \& Measuring the Performance of Completed Projects. https://www.michigan.gov/documents/energy/MLUI9 NARUC 420200 7.pdf.

National Audubon Society. 2020. "Wind Power and Birds; Properly sited wind power can help protect birds from climate change.” https://www.audubon.org/news/wind-power-and-birds.

National Oceanic and Atmospheric Administration Fisheries. Undated. "What does take mean under the Endangered Species Act and what is incidental take?"

https://www.fisheries.noaa.gov/node/8051.

New England Wind Energy Education Project. 2011. "Understanding the Current Science, Regulation, and Mitigation of Shadow Flicker: A NEWEEP Webinar." https://windexchange.energy.gov/webinars?id=2967\&search=Understanding + the + Current + Scien ce $\% 2 \mathrm{C}+$ Regulation $\% 2 \mathrm{C}+$ and + Mitigation + of + Shadow + Flicker $\% 3 \mathrm{~A}+\mathrm{A}+\mathrm{NEWEEP}+$ Webinar\#29 $\underline{67}$.

New York State Energy Research and Development Authority (NYSERDA). 2013. Wind Turbine-Related Noise: Current Knowledge and Research Needs. https://cris.nyserda.ny.gov/About/Publications/Research-and-Development-TechnicalReports/Wind-Reports.

NYSERDA. 2017. New York State Wind Energy Guidebook. https://www.nyserda.ny.gov/AllPrograms/Programs/Clean-Energy-Siting/Wind-Guidebook.

North Dakota Legislative Council. 2021. "Bill Actions for HB 1378." https://www.legis.nd.gov/assembly/65-2017/bill-actions/ba1378.html. 
O’Connor-Marer, Patrick. 2014. Aerial Applicator's Manual; A National Pesticide Applicator Certification Study Guide. National Association of State Departments of Agriculture Research Foundation. https://www.agaviation.org/Files/RelatedEntities/Aerial_Applicators Manual.pdf.

O’Melveny \& Myers LLP. 2018. "Offtake Structures for Wind Energy Projects." https://www.omm.com/resources/alerts-and-publications/alerts/energy-practice-newsletter-april$\underline{2018 / .}$.

Oteri, Frank. 2008. An Overview of Existing Wind Energy Ordinances. Golden, CO: National Renewable Energy Laboratory (NREL). NREL/TP-500-44439.

https://windexchange.energy.gov/files/pdfs/policy/2008/ordinances_overview.pdf.

Porter, Kevin, Svetlana Fink, Christina Mudd, Jennifer DeCesaro. 2009. Generation Interconnection Policies and Wind Power: A Discussion of Issues, Problems, and Potential Solutions. Golden, CO: National Renewable Energy Laboratory (NREL). NREL/SR-550-44508. https://www.nrel.gov/docs/fy09osti/44508.pdf.

Power Company of Wyoming LLC. 2015. Phase I Wind Turbine Development Site-Specific Plan of Development. Prepared for the U.S. Bureau of Land Management. https://eplanning.blm.gov/public_projects/nepa/58548/70964/77664/AppendixDPhase_I_Turbine_SPOD_Chapters1thru4.pdf.

Raptor View Research Institute. 2021. "Power Line Retrofit Project." https://www.raptorview.org/power-line-retrofit-project.html.

Solick, D., Pham, D., Nasman, K., Bay, K. 2020. Bat Activity Rates do not Predict Bat Fatality Rates at Wind Energy Facilities. https://bioone.org/journals/acta-chiropterologica/volume22/issue-1/15081109ACC2020.22.1.012/Bat-Activity-Rates-do-not-Predict-Bat-Fatality-Ratesat/10.3161/15081109ACC2020.22.1.012.full.

Stoel Rives. 2018. The Law of Wind: A Guide to Business and Legal Issues. Eighth Edition. http://files.stoel.com/files/books/LawofWind.PDF.

U.S. Department of Energy (DOE). 2015. Wind Vision: A New Era for Wind Power in the United States. https://www.energy.gov/sites/prod/files/2015/03/f20/wv_full_report.pdf.

Undated(a). "Wind Plants and Radar Interactions." WINDExchange Slideshows. https://windexchange.energy.gov/slideshows.

Undated(b). "Wind Turbine Sound." WINDExchange.

https://windexchange.energy.gov/projects/sound.

U.S. Energy Information Administration. 2021. "Electricity explained; Electricity in the United States.” https://www.eia.gov/energyexplained/electricity/electricity-in-the-us.php. 
U.S. Department of the Interior. 2009. Adaptive Management: The U.S. Department of Interior Technical Guide. https://www.doi.gov/sites/doi.gov/files/migrated/ppa/upload/TechGuide.pdf.

2017. “Mapping Sound.” https://www.nps.gov/subjects/sound/soundmap.htm.

U.S. Fish and Wildlife Service. 2012. Land-Based Wind Energy Guidelines. https://www.fws.gov/ecological-services/es-library/pdfs/WEG_final.pdf.

2019a. "Habitat Conservation Plans; Section 10 of the Endangered Species Act." https://www.fws.gov/midwest/endangered/permits/hcp/hcp_wofactsheet.html.

2019b. "Questions and Answers: Buckeye Wind Farm - Incidental Take Permit and Habitat Conservation Plan."

https://www.fws.gov/midwest/endangered/permits/hcp/buckeyewind/QAsBuckeyITPermit17July 2013.html.

2019c. "Mitigation Banking.” Texas Coastal Ecological Services Field Office. https://www.fws.gov/southwest/es/TexasCoastal/MitigationBanking.html.

2021. Habitat Conservation Plan Handbook. https://www.fws.gov/endangered/what-wedo/hep handbook-chapters.html.

U.S. Geological Survey. Undated. The U.S. Wind Turbine Database.

https://eerscmap.usgs.gov/uswtdb/.

VTT Technical Research Centre of Finland. 2020. "VTT studied the health effects of infrasound in wind turbine noise in a multidisciplinary cooperation study." https://www.vttresearch.com/en/news-and-ideas/vtt-studied-health-effects-infrasound-windturbine-noise-multidisciplinary.

Wiser, Ryan, and Mark Bolinger. 2019a. 2018 Wind Technologies Market Report. Berkeley, CA: Lawrence Berkeley National Laboratory.

https://www.energy.gov/sites/prod/files/2019/08/f65/2018\%20Wind\%20Technologies\%20Marke t\%20Report $\% 20$ FINAL.pdf.

Wiser, Ryan, and Mark Bolinger. 2019b. "Benchmarking Anticipated Project Lifetimes: Results from a Survey of U.S. Wind Industry Professionals.” Berkeley, CA: Lawrence Berkeley National Laboratory. https://emp.lbl.gov/publications/benchmarking-anticipated-wind-project.

Wiser, Ryan, Mark Bolinger, Ben Hoen, Dev Millstein, Joe Rand, Galen Barbose, Naïm Darghouth, Will Gorman, Seongeun Jeong, Andrew Mills, Ben Paulos. 2020. "Wind Energy Technology Data Update: 2020 Edition." Berkeley, CA: Lawrence Berkeley National Laboratory. https://emp.lbl.gov/sites/default/files/2020_wind_energy technology_data_update.pdf. 
